\title{
In situ characterization of mixed phase clouds using the Small Ice Detector and the Particle Phase Discriminator
}

\author{
P. Vochezer ${ }^{1}$, E. Järvinen ${ }^{1}$, R. Wagner ${ }^{1}$, P. Kupiszewski ${ }^{2}$, T. Leisner ${ }^{1}$, and M. Schnaiter ${ }^{1}$ \\ ${ }^{1}$ Institute for Meteorology and Climate Research - Atmospheric Aerosol Research, Karlsruhe Institute of Technology, \\ Karlsruhe, Germany \\ ${ }^{2}$ Laboratory of Atmospheric Chemistry, Paul Scherrer Institute, Villigen PSI, Switzerland \\ Correspondence to: M. Schnaiter (martin.schnaiter@kit.edu)
}

Received: 23 April 2015 - Published in Atmos. Meas. Tech. Discuss.: 30 June 2015

Revised: 4 December 2015 - Accepted: 12 December 2015 - Published: 20 January 2016

\begin{abstract}
Mixed phase clouds (MPCs) represent a great source of uncertainty for both climate predictions and weather forecasts. In particular, there is still a lack of understanding on how ice forms in these clouds. In this work we present a technique to analyze in situ measurements of MPCs performed with the latest instruments from the Small Ice Detector family. These instruments record high-resolution scattering patterns of individual small cloud particles. For the analysis of the scattering patterns we developed an algorithm that can discriminate the phase of the cloud particles. In the case of a droplet, a Mie solution is fitted to the recorded pattern and the size of the corresponding particle is obtained, which allows for a size calibration of the instrument. In the case of an ice particle, its shape is deduced from the scattering pattern.

We apply our data analysis method to measurements from three distinct MPC types. The results from laboratory measurements demonstrate that our technique can discriminate between droplets and ice particles in the same optical size range. This ability was verified by measurements at a mountain top station where we found an alternation of liquidand ice-dominated cloud regions. The analysis of results from aircraft-based measurements illustrates the ice detection threshold of the technique.
\end{abstract}

\section{Introduction}

Mixed phase clouds (MPCs) consist of both liquid water droplets and ice particles. Ice formation in MPCs is of great importance as it affects the cloud radiative properties and the clouds' development (e.g., Sun and Shine, 1994; Morrison et al., 2012). However, the processes which lead to ice in MPCs are still not well understood. In the mid-latitudes, ice in MPCs is expected to form via heterogeneous nucleation and secondary processes like the Hallett-Mossop process (Cantrell and Heymsfield, 2005). In the presence of liquid water droplets, ice particles are expected to grow rapidly, e.g., due to the Wegener-Bergeron-Findeisen process (Wegener, 1911; Bergeron, 1935; Findeisen, 1938). Therefore, the observation of small ice particles indicates recent ice formation either by droplet freezing or ice multiplication processes. In order to gain new insights into the ice formation processes in MPCs it is crucial to probe the smallest ice crystals with particle sizes below $50 \mu \mathrm{m}$. However, this is a challenging task as liquid droplets, in general, outnumber ice particles for particle sizes below $50 \mu \mathrm{m}$. An overview on different instruments for the in situ measurement of cloud particles is, e.g., given by (Wendisch and Brenguier, 2013, chapter 5). To determine the phase of cloud particles well below $50 \mu \mathrm{m}$ conventional imaging techniques (Abdelmonem et al., 2011; McFarquhar et al., 2013) as well as holography (Fugal and Shaw, 2009; Henneberger et al., 2013) are currently hardly applicable due to optical-resolution limitations. The resolution of such instruments is further lowered by the fact that the detection units are apart from the sensitive volume and that it is advantageous to probe a sensitive volume that is as large as possible. This hinders the phase discrimination of particles with dimensions below $20 \mu \mathrm{m}$. Instruments that record solely the single particle light-scattering intensity like the cloud droplet probe are well established for counting and sizing of cloud particles but they do not allow for a phase discrimina- 
tion (Baumgardner et al., 2011). A promising approach is to use polarized light to discriminate the phase of small cloud particles including those below $20 \mu \mathrm{m}$, as realized, e.g., in the Cloud Particle Spectrometer with Polarization Detection (CPSPD) (Baumgardner et al., 2014). However, the polarization ratio measured by the CPSPD depends on the particle orientation and particle size. Furthermore droplets have a non-negligible polarization ratio.

In this work the detection and detailed analysis of small cloud particles is carried out by instruments developed by the University of Hertfordshire, UK, that record near-forward scattering patterns of individual particles. The patterns depend on the size, shape, orientation, surface roughness, and internal structure of the cloud particles and provide detailed microphysical information even for sizes down to a few micrometers. The first version of the Small Ice Detector (SID1) has six discrete photomultipliers (Hirst et al., 2001). The upgraded second version of SID-2 has 28 azimuthally oriented detectors to measure a rough spatial light-scattering pattern (Cotton et al., 2010, 2013; Johnson et al., 2014). This work was conducted with the latest version, the SID-3 (identical to the instrument used by Ulanowski et al., 2012, and Ulanowski et al., 2014), as well as the lab version of this instrument called the Particle Phase Discriminator mark 2, Karlsruhe edition (PPD-2K), which is an slightly modified version of the instrument described in Kaye et al. (2008). Both the SID-3 and the PPD-2K record high-resolution scattering patterns and thus allow for an in-depth analysis of the phase and morphology of the scattering particle. Based on such patterns Ulanowski et al. (2012) presented a method to retrieve the size of complex particles. More recently, Ulanowski et al. (2014) presented a method to estimate the degree of particle roughness from the analysis of the particle's scattering pattern.

In this article we first describe the setup of the SID-3 and the PPD-2K. Subsequently, we present our technique to analyze the high-resolution scattering patterns and to deduce specific particle number concentrations from these measurements. Our method is a combination of existing approaches adapted for the SID-3/PPD-2K and novel extensions to analyze data obtained from MPCs. Within this work we analyze measurements taken at the AIDA cloud chamber, at the mountain top station Jungfraujoch, and from on board an aircraft over the Canadian Arctic.

The instrument and methods described in this paper were already used for a contribution to the study by Baumgardner et al. (2014), in which a quantitatively good agreement between the results of the PPD-2K and the CPSPD was obtained.

\section{Methods}

\subsection{SID-3 and PPD-2K design and operation}

The light source in both the SID-3 and the PPD-2K instrument is a frequency doubled Nd:YAG laser which emits $100 \mathrm{~mW}$ at a wavelength of $532 \mathrm{~nm}$ with linear polarization. The polarization of the beam is transformed to circular polarization by a quarter-wave plate and the maximum of the Gaussian beam is extracted by a set of apertures. The processed laser beam is similar to a step function with a rectangular cross section of $1500 \mu \mathrm{m} \times 160 \mu \mathrm{m}$ for the SID-3 before it hits the particles in the sensitive volume. Within the PPD$2 \mathrm{~K}$, the sample flow is focused on the larger laser beam. Behind the sensitive volume a beam dump is mounted that absorbs the direct laser beam as well as light scattered in the near-forward direction. Light scattered by the particle in a range of approx. 5 to $26^{\circ}$ relative to the forward direction runs through an optical assembly and impinges on an intensified camera which generates high-resolution scattering patterns at a resolution of $780 \times 582$ pixels and $582 \times 592$ pixels for the SID-3 and the PPD-2K, respectively. The camera exposure is triggered by the signal of a photomultiplier tube, henceforth denoted as trigger detector.

The practical implementation of this setup is different in both instruments. The SID-3 has an open path geometry and the sensitive area on the laser beam is defined by two trigger detectors. A schematic of this setup can be found in Johnson et al. (2014). The trigger detectors are aligned symmetrically along the laser beam axis and have a circular aperture with a half angle of $9.25^{\circ}$ at $50^{\circ}$ relative to the forward direction. The two trigger detectors have a different field of view (FOV) on the plane of the laser beam. The FOV of trigger detector one lies within the FOV of trigger detector two. In order to determine the sensitive area of the SID-3 trigger detectors we mounted a piezo electric droplet generator (GESIM GmbH, Grosserkmannsdorf, Germany), producing 60 to $90 \mu \mathrm{m}$ droplets on an $x-y-z$ stage. From these measurements we obtained the sensitive area of the SID-3 trigger detectors as $A_{\text {SID- } 3, T r}=0.47 \mathrm{~mm}^{2}$.

The FOV of the SID-3 camera is different from that of the trigger detectors and we determined it by applying a forced trigger signal onto the camera and placed a particle on a nonreflecting glass slide. The glass slide was mounted on an $x-$ $y-z$ stage and moved in the SID-3 laser beam. From these measurements we derived a sensitive area of the SID-3 camera of $A_{\text {SID-3,Cam }}=9 \mathrm{~mm}^{2}$.

In the PPD-2K the trigger detector records part of the forward-scattered light which is diverted by a beam splitter. Further details on the optical setup of the PPD-2K are given in Kaye et al. (2008). The sensitive areas of the PPD-2K trigger detector and camera are identical and are $A_{\mathrm{PPD}-2 \mathrm{~K}}=$ $2.5 \mathrm{~mm}^{2}$ (E. Hirst, Uni. Hertfordshire, personal communication, 2014). 
For both instruments the maximum acquisition rate of the trigger detector is $f_{\mathrm{t}}^{\max }=11 \mathrm{kHz}$ and the corresponding value of the camera is $f_{\mathrm{c}}^{\max }=30 \mathrm{~Hz}$. Whilst sampling MPCs we typically observe $f_{\mathrm{c}}^{\max }<f_{\mathrm{s}}<f_{\mathrm{t}}^{\max }$, where $f_{\mathrm{s}}$ is the rate of sampled particles. Thus the imaged particles are only a subsample of all particles that passed the instruments and we use the trigger count rate and pulse intensities to derive particle number concentrations and particle number size distributions.

\subsection{Analysis of particle number concentrations}

\subsubsection{Coincident particle sampling by the trigger detectors}

If two particles are in the sensitive volume at the same time they will generate an erroneous signal. For the following investigation of the probability of such a coincident sampling event, we assume that the hydrometeor sampling can be described by Poisson statistics. Following Johnson et al. (2014) we calculate the mean number of particles passing the sensitive volume of the instrument, $\lambda$, and the probability of more than one particle being present in this volume at the same time, $P(x>1, \lambda)$, as

$\lambda=n \cdot A \cdot d$,

$P(x, \lambda)=\frac{\lambda^{x} \exp (-\lambda)}{x !}$,

$P(x>1, \lambda)=1-(1+\lambda) \exp (-\lambda)$.

$n$ is the total number concentration of cloud particles, $A$ is the sensitive area of the instrument, and $d$ is the depth of the laser beams which is 160 and $120 \mu \mathrm{m}$ for the SID-3 and the PPD-2K, respectively. The size of a particle sampled by the SID-3 is deduced from the signal of trigger two which has a FOV of $1.35 \mathrm{~mm}^{2}$. In order to get a conservative estimate for coincident particle sampling by the SID-3 trigger detector, we use, in accordance with Johnson et al. (2014), the FOV of trigger two as the sensitive area of the SID-3 trigger detectors.

In case of the PPD-2K we use $A=A_{\mathrm{PPD}-2 \mathrm{~K}}$. For number concentrations of $20 \mathrm{~cm}^{-3}$ to $300 \mathrm{~cm}^{-3}, P(x>1, \lambda)$ given by Eq. (1c) is $9.4 \times 10^{-4}$ to $0.20 \%$ for the SID-3 trigger detector, and $1.8 \times 10^{-3}$ to $0.38 \%$ for the PPD-2K. For these values a coincident sampling probability of $1 \%$ is reached at particle number concentrations of 688 and $495 \mathrm{~cm}^{-3}$ for the SID-3 and the PPD-2K, respectively. Significant coincident sampling of particles by the trigger detectors of the SID-3 and the PPD-2K therefore only occurs for very high particle number concentrations.

In case of the PPD-2K the FOV of the trigger detector and the camera are identical; thus the coincidence consideration outlined above should also hold for the PPD-2K camera. The SID-3 camera, however, has a different FOV and a corresponding coincidence consideration is carried out in Sect. 2.3.1.

\subsubsection{Electronic dead time}

After a particle detection, the trigger electronics have a dead time of $8.00 \mu$ s (SID-3) and 8.25 $\mu$ s (PPD-2K). Particles passing the instrument during this dead time period are not detected and according to Johnson et al. (2014) the volume actively sampled by the instrument is reduced. Meaning that we use a smaller volume in the calculation of the number concentration deduced from the instruments. Assuming cloud particle number concentrations of 20 to $300 \mathrm{~cm}^{-3}$ and a typical flow speed for the SID-3 of $100 \mathrm{~m} \mathrm{~s}^{-1}$ and a PPD-2K sampling flow of $51 \mathrm{~min}^{-1}$, one gets a reduction in sample volume of 0.8 to $11.3 \%$ (for the SID-3) and 1.4 to $20.6 \%$ (for the PPD-2K). The presented data are corrected for the reduced sampling volume.

\subsection{Analysis of scattering patterns}

Figure 1 displays four selected high-resolution scattering patterns recorded with the PPD- $2 \mathrm{~K}$. The area between the inner green circle (at $7.4^{\circ}$ relative to the forward scattering direction) and the outer green circle (at $25.6^{\circ}$ relative to the forward scattering direction) is our region of interest (ROI). Using the LabVIEW (National Instruments, Inc., USA) software package we have developed an analysis routine for the SID-3 and PPD-2K forward scattering patterns. The idea for the analysis is to discriminate droplets and ice particles based on the azimuthal symmetry of their scattering patterns. The scattering pattern of a droplet is an Airy pattern with a perfect azimuthal symmetry. Scattering patterns of ice crystals have lower azimuthal symmetry. The final results of the analysis are: for droplets the particles' size based on Mie theory and for ice particles the shape and roughness. Ice particle roughness is not subject of this work but is investigated in an upcoming publication by Schnaiter et al. (2015). In detail the algorithm performs the following steps.

Initially a saturation ratio $q=N_{\mathrm{s}} / N_{\mathrm{a}}$ and a mean intensity $\bar{I}=\left(\sum_{i, j}^{N, M} I(i, j)\right) / N_{\mathrm{a}}$ for the ROI are calculated. Here $N_{\mathrm{s}}$ is the number of saturated pixels, $N_{\mathrm{a}}$ is the number of all pixels, and $I(i, j)$ is the gray level intensity of pixel $i, j$ in the ROI.

It is hard to give general threshold values for $q$ and $\bar{I}$ as the scattered intensity is a function of particle size and the gain of the camera is adjustable. However, a pattern is typically analyzed further if $q<0.2$ and $\bar{I}>3$ are fulfilled. These values are chosen in order to avoid the roughness analysis of patterns with too many saturated pixels as well as to avoid a significant contribution of background noise to the image in case of very low mean intensities. Images with $q \geq 0.2$ are very bright and typically their sizes exceed the range of which particles are investigated from.

In the next step, an unwrapped version of the ROI is generated which is equivalent to a change from Cartesian to polar coordinates and carried out by a bilinear interpolation. From the ROI in polar coordinates we compute a polar integrated 

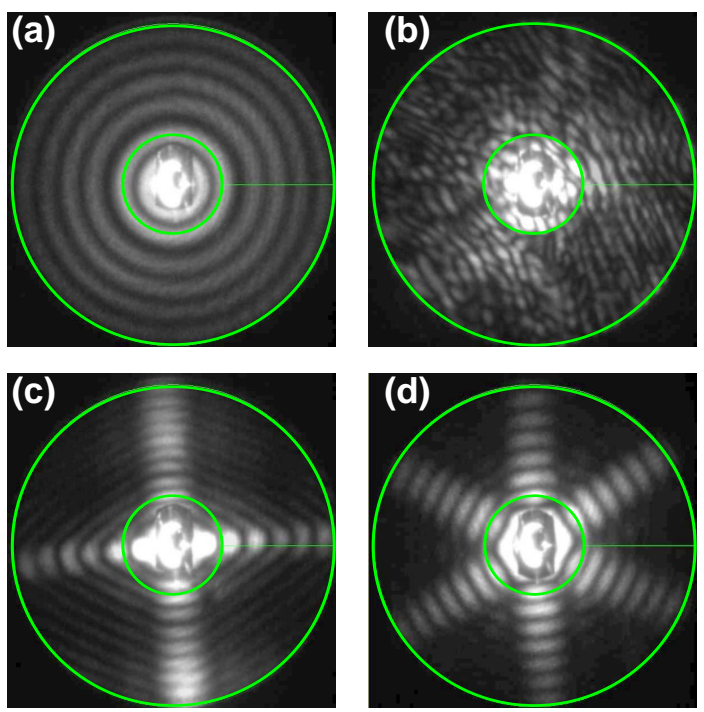

Figure 1. PPD-2K high-resolution scattering patterns of a droplet (a), an irregular ice particle (b), a columnar ice particle (c), and a hexagonal ice particle (d). A gamma correction is applied to the images for visibility.

azimuthal profile displayed in Fig. 2. A measure for the variation of these profiles is the variance of the intensity along the azimuthal angle:

$v_{\mathrm{az}}=\frac{\sum_{i=1}^{N}\left(x_{i}-\mu\right)^{2}}{N-1}$,

with $N$ the number of discrete angles of the azimuthal profile, $x_{i}$ the value of a certain element, and $\mu$ the mean value. Earlier instruments of the SID family do not record scattering patterns with a camera but have segmented trigger detectors instead. For the analysis of segmented trigger detector data, Hirst et al. (2001) introduced an asymmetry factor which is similar to $v_{\text {az }}$ given in Eq. (2). Cotton et al. (2013) tested and used the asymmetry factor to distinguish between liquid droplets and ice particles in MPCs. In the present work, we use the $v_{\mathrm{az}}$ values of the scattering patterns to discriminate between droplets and ice particles. Compared to the asymmetry factor deduced from earlier SID instruments $v_{\mathrm{az}}$ is based on high-resolution scattering patterns and thus contains more information and allows for a more sensitive phase discrimination.

For each experiment a specific variance threshold value, $v_{\mathrm{az}}^{\mathrm{thr}}$, is defined which is in the range of $6 \times 10^{-6}$ to $1 \times 10^{-5}$. Scattering patterns with $v_{\mathrm{az}}$ values in the vicinity of the threshold are manually crosschecked. The crosscheck allows us to reclassify or remove patterns with artifacts (e.g., right panel of Fig. 15).

\subsubsection{Coincident particle sampling by the camera}

It was already mentioned above in Sect. 2.2.1 that the FOVs of the trigger detector and the camera are identical in the

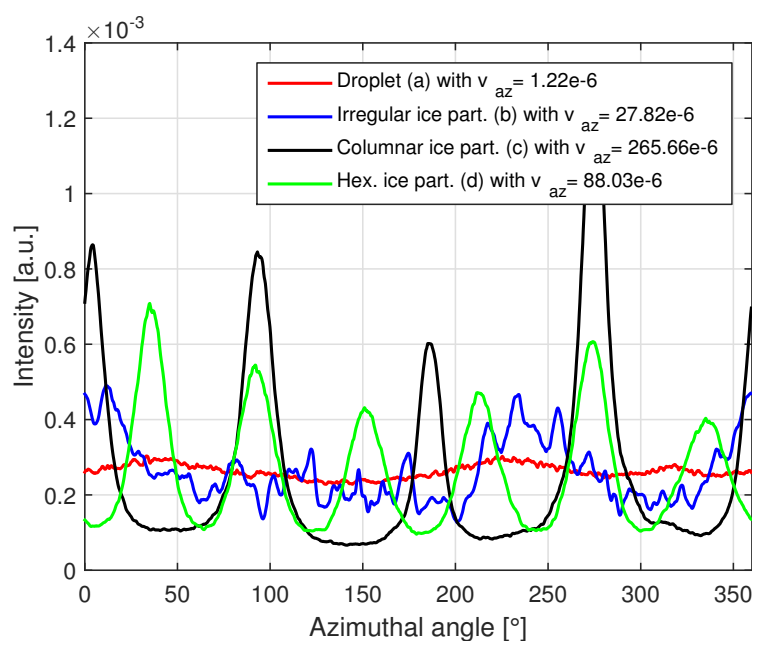

Figure 2. Polar integrated azimuthal intensities of the particles displayed in Fig. 1.

PPD-2K; thus the coincidence consideration outlined for the trigger detector should also hold for the PPD-2K camera. The SID-3 camera, however, has a different FOV, $A_{\text {SID-3,Cam, }}$ mentioned above. Using Eq. (1c) we calculate the probability for coincident sampling by the SID-3 camera as 0.04 to $7.03 \%$ for particle number concentrations of 20 to $300 \mathrm{~cm}^{-3}$. A coincident sampling probability of $1 \%$ is reached for a particle number concentration of $103 \mathrm{~cm}^{-3}$. A coincident sampling probability of up to $7 \%$ is significant, but scattering patterns with artifacts (e.g., from coincident particle sampling by the SID-3 camera) were carefully crosschecked as part of the manual inspection of the patterns. Such a manual crosscheck represents the best available method to avoid misclassification of scattering patterns due to coincident particle sampling by the SID-3 camera.

\subsubsection{Droplet analysis}

For $v_{\mathrm{az}}<v_{\mathrm{az}}^{\mathrm{thr}}$, the algorithm assigns a scattering pattern to correspond to a cloud droplet. From the scattering pattern an azimuthal integrated polar profile is deduced. Subsequently, an intensity profile of a spherical particle computed by Lorenz-Mie theory (Mie, 1908) with the complex refractive index of supercooled liquid water is fitted to the deduced profile as displayed in Fig. 3. In order to obtain the complex refractive index of water at a wavelength of $532 \mathrm{~nm}$, an interpolation between the values given by Segelstein (1981) was used. The temperature dependence of the refractive index is calculated by applying the Lorentz-Lorenz relation together with the parametrization of the water density as a function of temperature given by Hare and Sorensen (1987). Based on these calculations we determined a mean complex refractive index of $m=1.337+i 5 \times 10^{9}$ for $T \in\left[-30,+10^{\circ} \mathrm{C}\right]$.

The fit procedure involves the following two steps. We obtain a first diameter of the droplet by determining the num- 


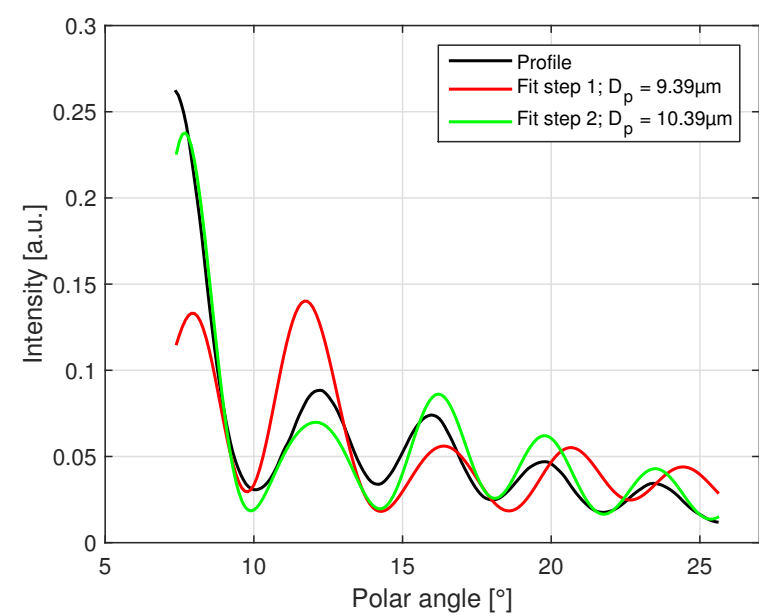

Figure 3. Azimuthal integrated polar intensity of the cloud droplet displayed in Fig. 1a. The two computations of Mie solutions given by the fit routines are displayed as well.

ber and the positions of the maxima in the angular profile. These values are compared to values calculated in advance and stored in a lookup table. The lookup table is calculated for $D_{\mathrm{p}} \in[2.5,60 \mu \mathrm{m}]$ at a resolution of $0.01 \mu \mathrm{m}$. For a given measured angular profile we determine the calculated profile for which the number of maxima agree and the deviation in the maxima positions is minimal. The diameter of this calculated profile is our first diameter for the droplet under investigation.

The diameter from the first step is the starting point for the second fit, which is a least mean square fit of a complete Mie calculation to the measured profile. The second fit yields a refined result for the droplet diameter.

\subsubsection{Size calibration}

It was mentioned in Sect. 2.1 that the instruments typically record a trigger signal for every sampled cloud particle. However, scattering patterns are only obtained for a subset of these particles. In order to generate number size distributions from the trigger count rate and pulse intensities we conduct a size calibration. For this purpose, we use an ensemble of successfully fitted droplet patterns. The calibration function linking the fitted exact analytic size of the individual droplets with the corresponding intensity recorded by the trigger detector is given by Cotton et al. (2010) as

$D_{\mathrm{p}}=a \cdot I^{b}$,

where $D_{\mathrm{p}}$ is the particle diameter and $I$ is the intensity recorded by the trigger detector. The prefactor $a$ is a function of the laser power and of the gain applied to the trigger detector which can be adjusted. The exponent $b$ is obtained as follows. For the left panels of Figs. 4 and 5, we applied Lorenz-Mie theory to calculate the irradiances of a certain droplet size. Therefore the angular dependent Mie function
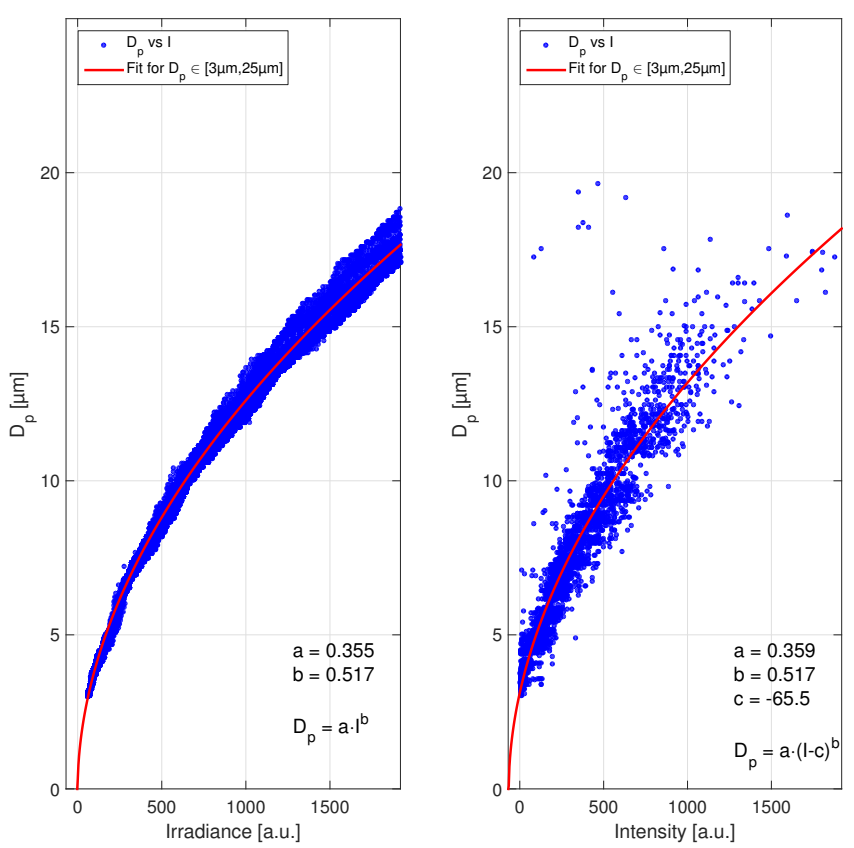

Figure 4. Size calibration of the SID-3 trigger detector. Left panel: scattered irradiances for a circular aperture with a half angle of $9.25^{\circ}$ at $50^{\circ}$ relative to the forward direction calculated by LorenzMie theory for water droplets. Right panel: analysis result obtained from the measurement of a dense droplet cloud during RICE 01 at the AIDA chamber.

for a certain droplet size was integrated over the solid angles of the detectors. It is noteworthy that the calculated values differ from the fit function, but there are no clear ambiguities like for other cloud probes, e.g., Lance et al. (2010). For the SID-3, the trigger detector has a circular aperture with a half angle of $9.25^{\circ}$ at $50^{\circ}$ relative to the forward direction. In the case of the PPD-2K the trigger detector covers 7.4 to $25.6^{\circ}$ relative to the forward direction. We fitted the calibration function Eq. (3) to these computed data sets. This fit yields a value for $b$ which is fixed for the calibration fits to measured data sets displayed in the right panels of Figs. 4 and 5. An additional variable $c$ in the SID-3 calibration function, $D_{\mathrm{p}}=a \cdot(I-c)^{b}$, is added to account for the fact that the value given by the SID-3 trigger detector is a measure of the area under the intensity peak rather than a measure of the absolute peak height. For the PPD-2K, however, the intensity recorded by the trigger detector is deduced from the peak height and Eq. (3) is applied. An alternative measure for the size of the imaged particles is the mean intensity of the scattering pattern recorded by the camera. Figure 6 shows such a size calibration. For small droplet sizes the oscillating pattern predicted by Lorenz-Mie theory is reproduced by the measurements. Whereas for larger droplets there is a discrepancy in the mean image intensity between measurement and fit function which most likely originates from a nonlinear behavior of the intensifier-camera unit. 

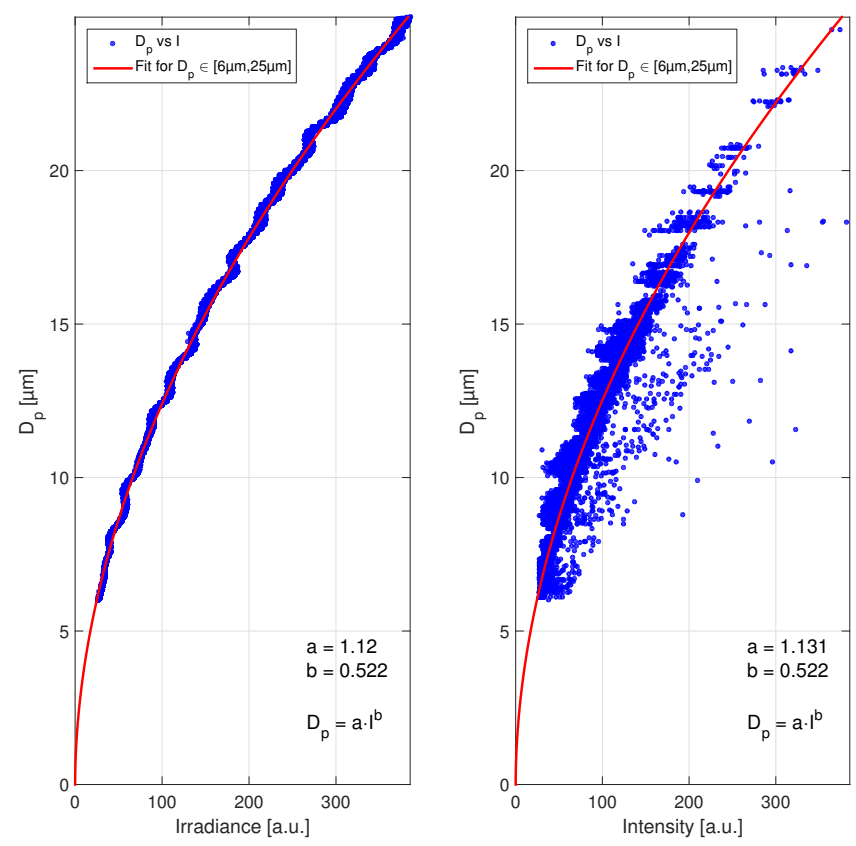

Figure 5. Size calibration of the PPD-2K trigger detector. Left panel: scattered irradiances in 7.4 to $25.6^{\circ}$ forward direction calculated by Lorenz-Mie theory for water droplets. Right panel: analysis result obtained from the measurement of a dense droplet cloud during RICE 01 at the AIDA chamber. The spread of the data points is mainly due to electronic noise.

The above-mentioned procedure allows for a calibration of the intensity recorded by the trigger detector against the exact size given by a fit of a Mie solution for every data set with a sufficient number of liquid droplets. In the following, the diameter of a particle, $D_{\mathrm{p}}$, is the scattering equivalent diameter of a water droplet.

\subsubsection{Ice particle shape classification}

Scattering patterns with $v_{\mathrm{az}}>v_{\mathrm{az}}^{\text {thr }}$ are assigned to correspond to ice particles and the particles' shape is analyzed. The shape classification performed by our software is adopted from Ulanowski et al. (2007) and Stopford et al. (2008) and is based on a discrete fast Fourier transform (DFT) of the polarintegrated azimuthal intensity profile (Fig. 2). The DFT of an input sequence $x_{l}$ of length $M$ is defined as

$y_{k}=\sum_{l=0}^{M-1} x_{l} \exp ^{-i 2 \pi k l / M}$.

$y_{k}$ are called Fourier coefficients and constitute the transform output $Y$. For the classification we search for the maximum of $Y$ excluding $y_{0}$. When finding a maximum of $Y$ above a threshold of 0.005 we distinguish between three classes of particles. A pattern corresponding to a columnar particle has maxima for $y_{2}$ or $y_{4}$. In case we find a maximum for $y_{3}, y_{6}$, or $y_{9}$ the particle is classified as hexagonal. In all other cases, in-
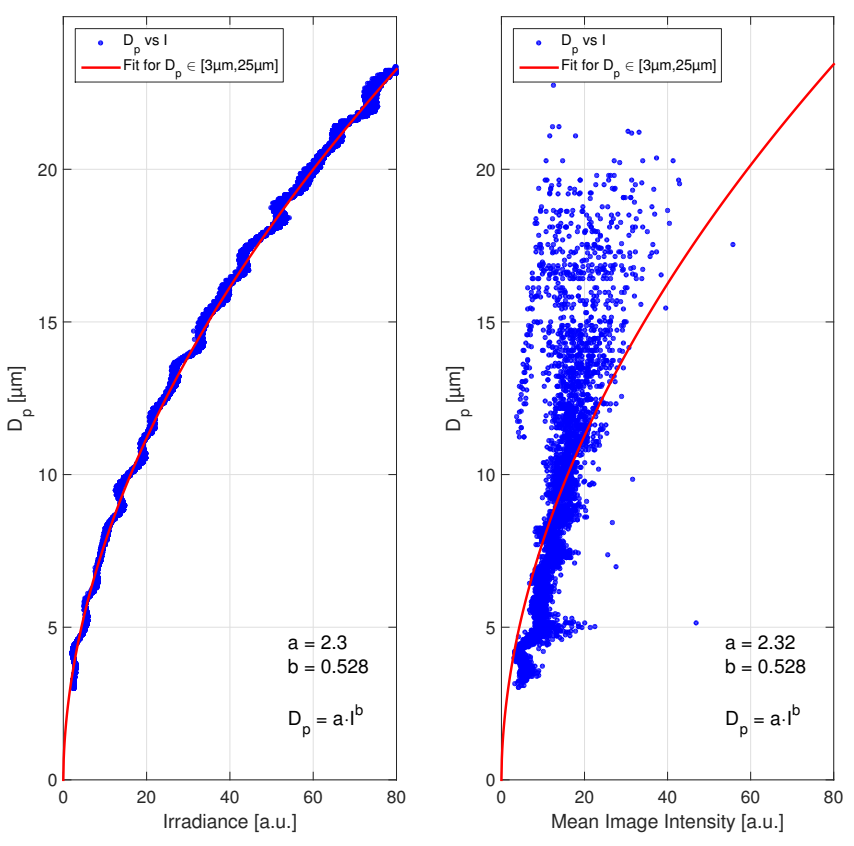

Figure 6. Size calibration of the SID-3 mean image intensity. Left panel: scattered irradiances in 7.0 to $23.5^{\circ}$ forward direction calculated by Lorenz-Mie theory for water droplets. Right panel: analysis result obtained from the measurement of a dense droplet cloud during RICE 01 at the AIDA chamber.

cluding when no maximum was found, we assign the pattern to the irregular shape class. Representatives for the irregular (labeled with b), the column (labeled with c), and hexagonal (labeled with d) classes as well as the corresponding intensity profiles are shown in Figs. 1 and 2.

This ice shape classification can be affected by the orientation of the particle like outlined in Ulanowski et al. (2006). For the following it is important to note that ice typically crystallizes with hexagonal symmetry (Pruppacher and Klett, 1997). We regard, for example, the scattering pattern of a columnar ice particle in Fig. 1c. The corresponding particle is a column which is aligned top to bottom at 9 to 3 o'clock (as seen from the camera) perpendicular to the incident beam direction. By a rotation in the plane perpendicular to the incident beam direction, e.g., by $90^{\circ}$ to the position (12 to 6 o'clock), the scattering pattern will be rotated by $90^{\circ}$. The presented habit classification is based on the Fourier transformation of the azimuthal profiles (Fig. 2). Thus such a variation in particle orientation would lead to a shift of the profile along the $x$ direction only. The Fourier transform, and thus the classification, is unaffected by such a shift.

However, if the particle of Fig. 1c rotates parallel to the incident beam direction, the pattern will be affected differently. In the case that the basal facet of the particle (top or bottom) faces the camera, the particle appears to have hexagonal symmetry as seen by the camera. Thus a scattering pattern like in Fig. 1d will be generated. For intermediate orientations the 
scattering pattern of a hexagonal column will be a mixture of Fig. 1c and d with bended arcs (see Ulanowski et al., 2006, Fig. 12). This ambiguity in the detection of columnar and plate-like particles with six-fold symmetry is the reason why we combine the classes of columnar and hexagonal particles into a single pristine particle class. Thus a classification of ice particles as irregular or pristine is robust against a variation of particle orientation.

In order to link the observed scattering patterns to real shapes, a first comparison of SID-3 data and T-matrix calculations was published in Tricoli et al. (2015) and an extension to larger sizes is ongoing.

\subsection{Quantification of specific particle types}

During cloud sampling typically $f_{\mathrm{c}}^{\max }<f_{\mathrm{s}}<f_{\mathrm{t}}^{\max }$ holds (Sect. 2.1). Thus the group of imaged particles represents a subset of all cloud particles which passed through the instruments and were detected by the trigger detectors. From the numbers of observed certain scattering patterns we derive fractions of specific particle classes and subclasses (e.g., ice particles, columnar ice particles, rough ice particles). Multiplication of those number-based fractions with the total number concentration yields specific particle number concentrations. In this work we focus on ice particles as a specific particle type, so that we can derive the ice particle fraction and droplet fraction in mixed phase cloud situations. However, this method can be applied to any particle type that can be distinguished by analysis of the scattering patterns. In the following we consider the error due to the fact that the imaged particles are a subset of all sampled particles. The upper and lower errors, $p_{+}$and $p_{-}$, of a specific particle type fraction, $p$ (e.g., ice fraction), can be calculated from the "ClopperPearson confidence limits" (Barlow, 1989) as

$$
\begin{aligned}
& \sum_{r=x+1}^{N} B\left(r, p_{+}, N\right)=\frac{1+C}{2}, \\
& \sum_{r=0}^{x-1} B\left(r, p_{-}, N\right)=\frac{1+C}{2},
\end{aligned}
$$

where $B(r, p, N)$ is the binomial probability distribution, $x$ is the number of successes (e.g., number of detected ice patterns), and $N$ is the total number of scattering pattern images under consideration. Equation (5a) defines $p_{+}$such that the probability to obtain more than $x$ successes out of $N$ trials is $(1+C) / 2$. $p_{-}$is defined such that the probability to obtain less than $x$ successes out of $N$ trials is $(1+C) / 2$, where $C$ is the confidence level. $C$ is typically set to $68.27 \%$, meaning that $\left[p_{-}, p_{+}\right]$represents the one $\sigma$ interval. $p_{+}$and $p_{-}$ are computed numerically and are, e.g., the boundaries for the derived ice fraction. As mentioned above, number concentrations of specific particles types are obtained by multiplication of the total particle number concentration with the specific particle fraction. The uncertainty of a calculated specific particle number concentration is obtained by Gaussian error propagation of both factors. The errors of a specific particle fraction are $p-p_{-}$and $p+p_{+}$. The uncertainty in the total number concentration is due to uncertainties with regards to the sampled volume.

In the last part of this section the detection limit of the instruments with regards to a specific particle type is elaborated. If $p$ (e.g., the ice fraction) in the sampled cloud parcel is 0 the probability to detect a specific (e.g., ice) scattering pattern is 0 . With increasing $p$, the probability to detect a specific scattering pattern increases. We define the detection threshold $p_{\text {thr }}$ as

$$
\begin{aligned}
0.5 & =B\left(0, p_{\mathrm{thr}}, N\right) \\
& =\left(1-p_{\mathrm{thr}}\right)^{N},
\end{aligned}
$$

where the number of scattering patterns under investigation is $N=f_{\mathrm{c}} \cdot t_{\mathrm{av}}$, with $f_{\mathrm{c}}$ the image rate of the camera and $t_{\mathrm{av}}$ the averaging time of the data. Equation (6a) defines $p_{\text {thr }}$ such that it is equiprobable to detect no specific (e.g., ice) pattern and to detect specific patterns. For a typical mixed phase cloud data set, $f_{\mathrm{c}}=f_{\mathrm{c}}^{\max }=30 \mathrm{~Hz}$ holds and $t_{\mathrm{av}} \in[1,600 \mathrm{~s}]$. Under these conditions Eq. (6b) can be written as $p_{\mathrm{thr}} \approx a / t_{\mathrm{av}}$ with $a=0.023 \mathrm{~s}$.

Figure 7 illustrates the effect of subsampling on the ice detection threshold of the instruments. With an increase in averaging time, statistics of the measurement improve and the ice detection threshold decreases. This finding can be generalized from ice particles to all other specific particle types that the SID-3 or PPD-2K can distinguish.

\subsection{Measurement locations}

In this work, we present measurements which were obtained from three different cloud types at three distinct locations. These are artificial clouds generated in a cloud chamber facility at the Karlsruhe Institute of Technology (KIT), Germany; natural orographically induced clouds which were probed at the mountain top research station Jungfraujoch, Switzerland; and natural arctic MPCs over the Beaufort sea, NWT, Canada, sampled from on board an aircraft.

\subsubsection{The AIDA cloud chamber of KIT}

The Aerosol Interaction and Dynamics in the Atmosphere (AIDA) cloud chamber of KIT is a $84 \mathrm{~m}^{3}$ stainless steel vessel and can be operated in the temperature range from -90 to $60{ }^{\circ} \mathrm{C}$ for atmospherically relevant humidity, trace gas, and aerosol conditions. Clouds are generated in the chamber by controlled expansion cooling experiments of the chamber gas at near-constant wall temperatures. Further details of the chamber operation and instrumentation can be found in Möhler et al. (2005), Wagner et al. (2011), Schnaiter et al. (2012), and Skrotzki et al. (2013). In this work, data from the following instruments mounted at the AIDA are used.

- Thermocouples type $\mathrm{k}$ for measuring the gas and wall temperature. 


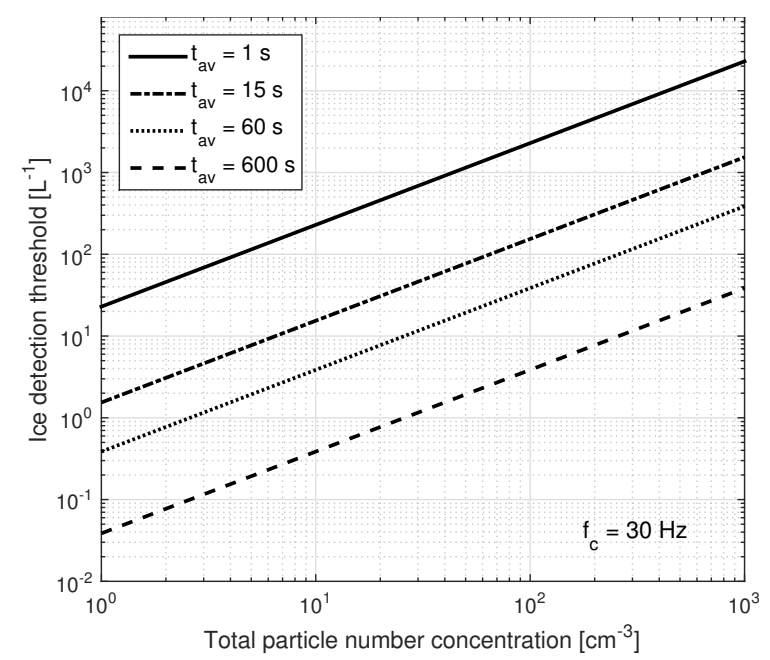

Figure 7. The SID-3 and PPD-2K ice detection threshold as a function of the total particle number concentration. The concept of the detection threshold can be generalized from ice particles to all specific particle types distinguishable by means of SID-3/PPD-2K scattering patterns.

- A Baratron ${ }^{\circledR}$ (MKS, Germany) pressure sensor.

- A tunable diode laser (TDL) setup which measures the water vapor partial pressure.

- A dew point hygrometer (Dew point mirror 373, MBW, Switzerland) with a heated inlet that determines the total (evaporated cloud particle and gas phase) water concentration.

- An optical particle counter (type WELAS2000, Palas, Germany) with a detection range of 2.3 to $107 \mu \mathrm{m}$. The WELAS instrument detects light scattered by the particles at $90^{\circ}$ relative to the forward direction. The analysis of the WELAS results involves an optical size threshold to distinguish between droplets and ice.

- The scattering and depolarization instrument (SIMONE) which records light scattered by an ensemble of cloud particles inside the AIDA chamber Schnaiter et al. (2012); Järvinen et al. (2014). The forward-scattered light is detected at an angle of $2^{\circ}$ and the backwardscattered light at $178^{\circ}$. The backward-scattered light is split into its vertically and horizontally polarized components to determine the depolarization ratio of the initially linearly polarized light.

In this work we present data obtained during the Rough ICE (RICE 03) campaign which took place in December 2014. The SID-3 and PPD-2K were mounted in custommade housings directly underneath the AIDA chamber. Each housing is equipped with a dedicated inlet that protrudes into the chamber volume for cloud particle sampling. The hous- ings are connected to a flow control system that maintains constant mass flows through the instruments.

\subsubsection{High-altitude research station Jungfraujoch}

The high-altitude research station Jungfraujoch is situated at $3568 \mathrm{~m}$ a.s.l. on a mountain col in the Bernese alps, Switzerland. The station is frequently in clouds with an annual mean cloud frequency of $37 \%$ (Baltensperger et al., 1998). During winter time ambient temperatures at the station can drop to $-30^{\circ} \mathrm{C}$ and thus the station is well suited for MPC sampling. The measurements presented here were obtained in February 2013 as part of the cloud and aerosol characterization experiment (CLACE 2013) which was a joint campaign of 10 international institutes (Kupiszewski et al., 2015; Worringen et al., 2015; Schmidt et al., 2015). The SID-3 was mounted on a $2.3 \mathrm{~m}$ high platform which aligned itself to the wind direction. Furthermore the SID-3 was equipped with an aspiration unit in order to maintain a constant particle flow through the instrument. In addition, but not further elaborated here, we performed measurements with the PPD-2K as part of the novel Ice selective Inlet (ISI) which is presented in detail in Kupiszewski et al. (2015). Meteorological parameters like wind speed, wind direction, ambient temperature, and relative humidity measurements at the Jungfraujoch site were measured by MeteoSwiss as part of the Global Atmosphere Watch monitoring program (Spiegel et al., 2012; Hammer et al., 2014).

\subsubsection{Arctic mixed phase clouds over the Beaufort Sea}

In April and May Arctic MPCs frequently develop over the Beaufort Sea and can persist for up to several days (Intrieri et al., 2002; Shupe et al., 2006; Mioche et al., 2015). In this article, we present measurements obtained during the VERtical Distribution of Ice in Arctic Clouds (VERDI) campaign which was a joint campaign of seven German research institutions and took place in April and May 2012 (Klingebiel et al., 2015). Measurements were carried out on board the Polar-5 research aircraft north of the Mackenzie River delta over the Beaufort Sea (around $70^{\circ} \mathrm{N}$ ) north of Inuvik, NWT, Canada. During VERDI the SID-3 was mounted underneath the wing of the Polar-5 which is a Basler BT-67 operated by the Alfred Wegener Institut (AWI), Bremerhaven, Germany. The Polar-5 has a low mean cruising speed of $60 \mathrm{~m} \mathrm{~s}^{-1}$ which enables for a relatively high spatial resolution of the SID-3 measurements in comparison with measurements from other aircraft platforms.

\section{Results}

\subsection{AIDA cloud chamber measurements}

The first experiment to be presented here is expansion run 27 conducted during the RICE 03 campaign at the AIDA cloud 
(a)

(b)

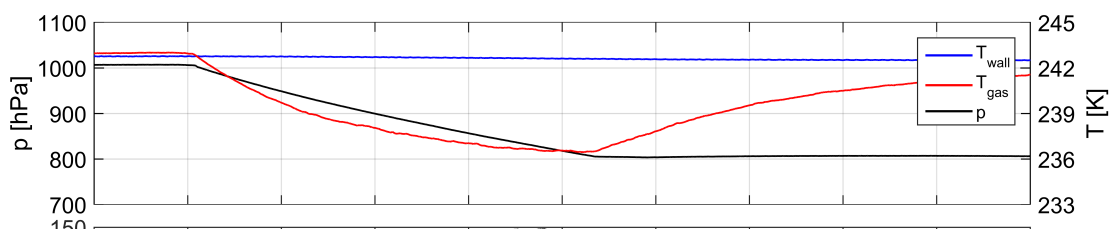

(c)

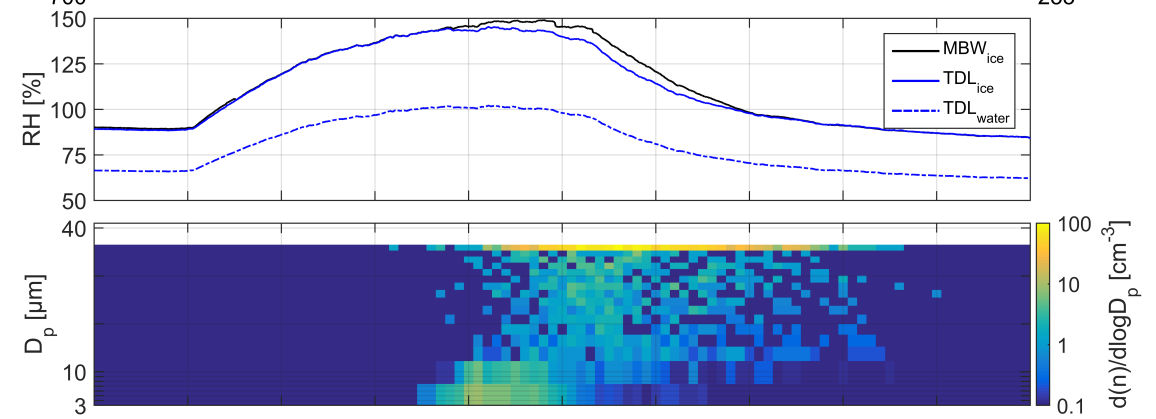

(d)

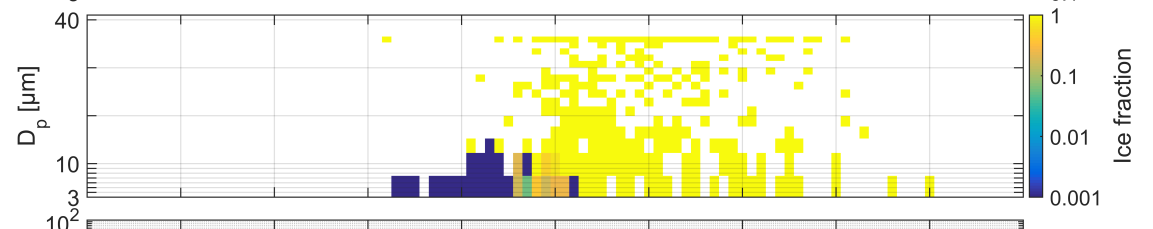

(e)

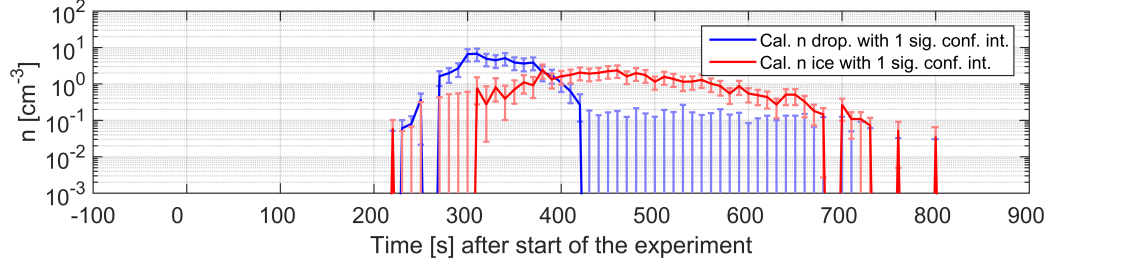

Figure 8. SID-3 measurement, with $t_{\mathrm{av}}=10 \mathrm{~s}$, at the AIDA cloud chamber during the RICE 03 campaign expansion run 27. In (a) the pressure and temperature in the AIDA vessel during the course of the experiment are displayed. At $t=0 \mathrm{~s}$, the experiment is started by lowering the pressure which initiates a quasi-adiabatic expansion of the air in the chamber. (b) displays the relative humidity in the chamber where the difference between the $\mathrm{MBW}_{\text {ice }}$ and $\mathrm{TDL}_{\text {ice }}$ values indicates the presence of cloud particles. (c) shows the particle number size distribution measured by the SID-3. (d) displays the size-resolved ice fraction over the course of the experiment. The ice fraction is calculated from the numbers of observed ice and droplet patterns. In (e), the calculated droplet and ice particle number concentrations are displayed.

chamber. During this experiment a liquid-dominated cloud was transformed via a mixed phase state into a pure ice cloud through homogeneous freezing. These measurements illustrate the instrument's response to a liquid, mixed phase, and ice cloud. Figures 8 and 9 show the course of the experiment including measurements of the SID-3 and PPD-2K. Prior to the cloud expansion run, a mixture of sulfuric acid and Argentinian soil dust (ASD) aerosol was added to the chamber with an initial total number concentration of $100 \mathrm{~cm}^{-3}$. The sulfuric acid to soil dust number ratio was about $50: 1$ at the start of the expansion run. The panels a and b of Fig. 8 display the thermodynamic state of the AIDA chamber. For negative time values the chamber is at near-ice-saturated conditions with a relative humidity with respect to ice of $90 \%$ and a gas temperature of $243 \mathrm{~K}$. The start of the expansion experiment $(t=0 \mathrm{~s})$ is defined by the opening of a valve between the vessel and a pump which initiates a quasi-adiabatic expansion in the chamber. As the pressure and the gas temperature decrease, the relative humidity increases during the expansion cooling. When the relative humidity with respect to liquid water exceeded $100 \%$ (at $t \approx 215 \mathrm{~s}$ ), the aerosol particles were activated to form cloud droplets. The difference between the $\mathrm{MBW}_{\text {ice }}$ and $\mathrm{TDL}_{\text {ice }}$ values shown in Fig. $8 \mathrm{~b}$ is caused by condensed water on hydrometeors and thus indicates the presence of cloud particles. The presence of cloud droplets with $D_{\mathrm{p}}<15 \mu \mathrm{m}$ is also indicated by the SID-3 measurements displayed in panels c, d, and e of Fig. 8. The cloud droplet mode is most pronounced at $t \approx 300 \mathrm{~s}$ and visible by yellowish colors for the smallest $D_{\mathrm{p}}$ values in panel c, blueish colors in panel $\mathrm{d}$, and the peak of the droplet number concentration in panel e. The small number of ice particles detected in the early stages of the droplet formation must have been heterogeneously nucleated on the ASD either via condensation or immersion freezing. The expansion was continued until the gas temperature approached the onset temperature for homogeneous freezing of water droplets at around $237 \mathrm{~K}$. At this point of the experiment a rapid and complete glaciation of the droplet cloud took place. The process of homogeneous ice formation in the AIDA cloud chamber is described in (Benz et al., 2005). The onset of homogeneous ice nucle- 
(a)

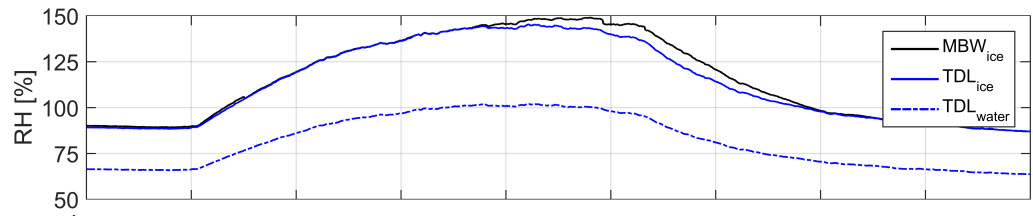

(b)

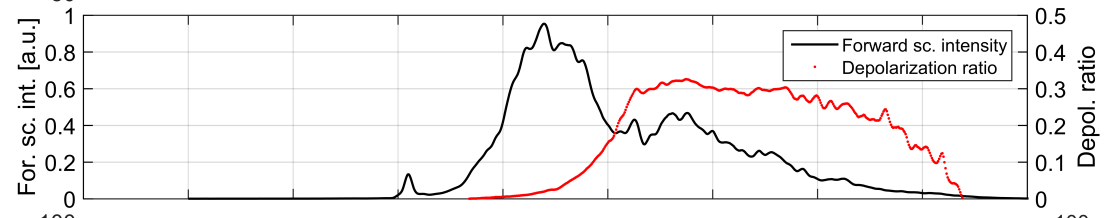

(c)
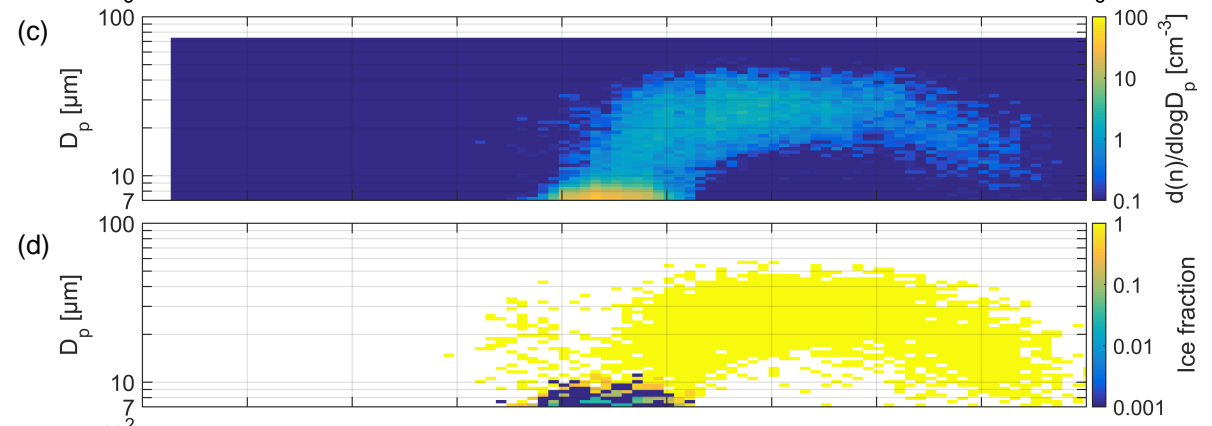

(e)

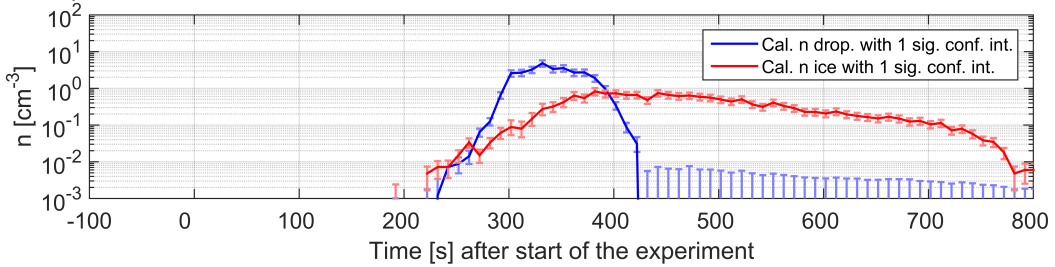

Figure 9. PPD-2K measurement, with $t_{\mathrm{av}}=10 \mathrm{~s}$, at the AIDA cloud chamber during RICE 03 campaign expansion run 27. In (a), the relative humidity measurements from Fig. $8 \mathrm{~b}$ are displayed. (b) shows a plot of the SIMONE measurements during this expansion run. The forwardscattered intensity indicates the presence of cloud particles in the chamber. The depolarization ratio depends on the phase of the particles. (c) displays the number size distribution of cloud particles measured by the PPD-2K. (d) shows the size-resolved ice fraction over the course of the experiment. The ice fraction is calculated from the numbers of observed ice and droplet patterns. In (e), the calculated droplet and ice particle number concentrations are displayed.

ation is clearly detected by the SID- 3 around $310 \mathrm{~s}$ as the ice number concentration increases in Fig. 8e. The homogeneous freezing can also be seen by the changing color in the smallest size bins in panel d. After about $410 \mathrm{~s}$ the SID-3 detected only ice particles, meaning that there was a MPC in the AIDA for about $100 \mathrm{~s}$.

A different graphical representation of the same experiment is shown in Fig. 9. Panel b shows SIMONE and panels $c$ to e show PPD-2K instead of the SID-3 measurements. The increase in the forward scattering intensity measured by SIMONE (panel $b$ ) indicates the presence of cloud particles in the chamber. This increase correlates well with the increase in number concentration as observed by the PPD-2K, shown in panel e). In addition, a depolarization ratio is deduced from the SIMONE measurements. The depolarization ratio is determined for multiple particles simultaneously present in the sensitive volume and depends on the phase of these particles. At the beginning of the experiment the depolarization ratio is around 0 which is typical for mainly liquid clouds. At $310 \mathrm{~s}$ the depolarization ratio starts to increase, indicating the onset of homogeneous freezing, also detected by the PPD-2K and the SID-3. During the MPC phase the depolarization ratio increases as the glaciation advances. The constant depolarization ratio of 0.3 , reached after about $410 \mathrm{~s}$, is in accordance with a full glaciation of the cloud. In summary, the results from the SIMONE measurement are in good agreement with the PPD-2K and the SID-3 observations.

To test our liquid-ice discrimination method, Fig. 10 displays the $v_{\mathrm{az}}$ values as a function of $D_{\mathrm{p}}$ for all scattering patterns recorded during RICE 03 expansion run 27 by the SID-3 (left panel) and PPD-2K (right panel). As mentioned above, $D_{\mathrm{p}}$ is the optical particle diameter equivalent to a liquid sphere and is deduced from the trigger intensity. In this plot a clear separation between the droplet and ice clusters is obvious. The scattering patterns between the clusters are manually crosschecked as noted in Sect. 2.3 but for this experiment an automated discrimination with $v_{\mathrm{az}}^{\mathrm{thr}}$ is applicable.

The glaciation of the droplet cloud observed by the SID-3, PPD-2K, and the SIMONE instrument was also detected by the WELAS optical particle counter that is installed perma- 

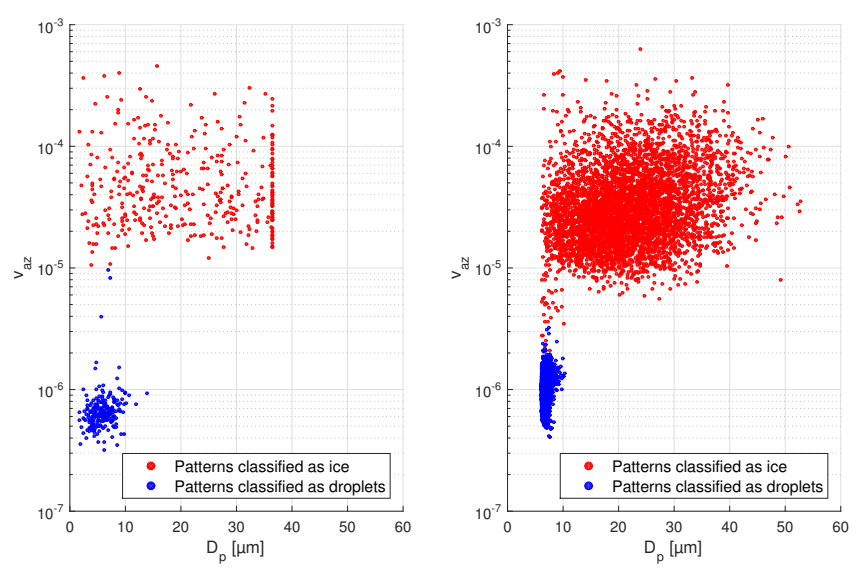

Figure 10. The variance of the polar integrated azimuthal profile as a function of the optical droplet equivalent diameter deduced from the trigger intensity for scattering patterns during the AIDA MPC experiment RICE 03 expansion run 27. Patterns were recorded by the SID-3 (left panel) and by the PPD-2K (right panel). The experiment is displayed in Figs. 8 and 9. The patterns with $v_{\mathrm{az}}>2 \times 10^{-6}$ were manually crosschecked.

nently at the AIDA chamber. Figure 11 displays a comparison of the number concentrations deduced from the WELAS instrument, the SID-3, and the PPD-2K. The relatively high size detection threshold of the PPD-2K (approx. $D_{\mathrm{p}}>7 \mu \mathrm{m}$; see Figs. 9c, 8c) leads to relatively low ice particle number concentrations. This is due to the calculation of the ice particle number concentration as the product of the ice fraction and the total number concentration. The detected total number concentration is decreased by the size detection threshold especially for ice particles as they scatter less light in the near-forward direction than droplets (McFarlane and Marchand, 2008). Neglecting the relatively low level of the PPD$2 \mathrm{~K}$ values the curves of the number concentrations from the WELAS, SID-3, and PPD-2K agree well.

After the discussion of a liquid-glaciated transition experiment, which included a relatively short MPC period, we present another experiment, namely expansion run 46 of the RICE 03 campaign, depicted in Fig. 12. The subject of this experiment is a stable MPC at relatively high gas temperatures $(253 \mathrm{~K}$ at $t=0 \mathrm{~s})$. Prior to the expansion run ASD aerosol, with a number concentration of $20 \mathrm{~cm}^{-3}$, was present in the AIDA chamber. This cloud represents one of our best attempts to mimic natural MPCs in the AIDA chamber. In panel $b$ of Fig. 12 the depolarization ratio measured by the SIMONE instrument during the course of the experiment is shown. The depolarization ratio increases at the beginning of the experiment as the glaciation starts but quickly reaches a constant value of 0.1 . The low depolarization ratio is an indication of a MPC, since higher depolarization values for an ensemble of ice particles with sizes of 5 to $100 \mu \mathrm{m}$ are expected. Furthermore, in contrary to experiment 27, the depolarization ratio remains constant throughout the expan-
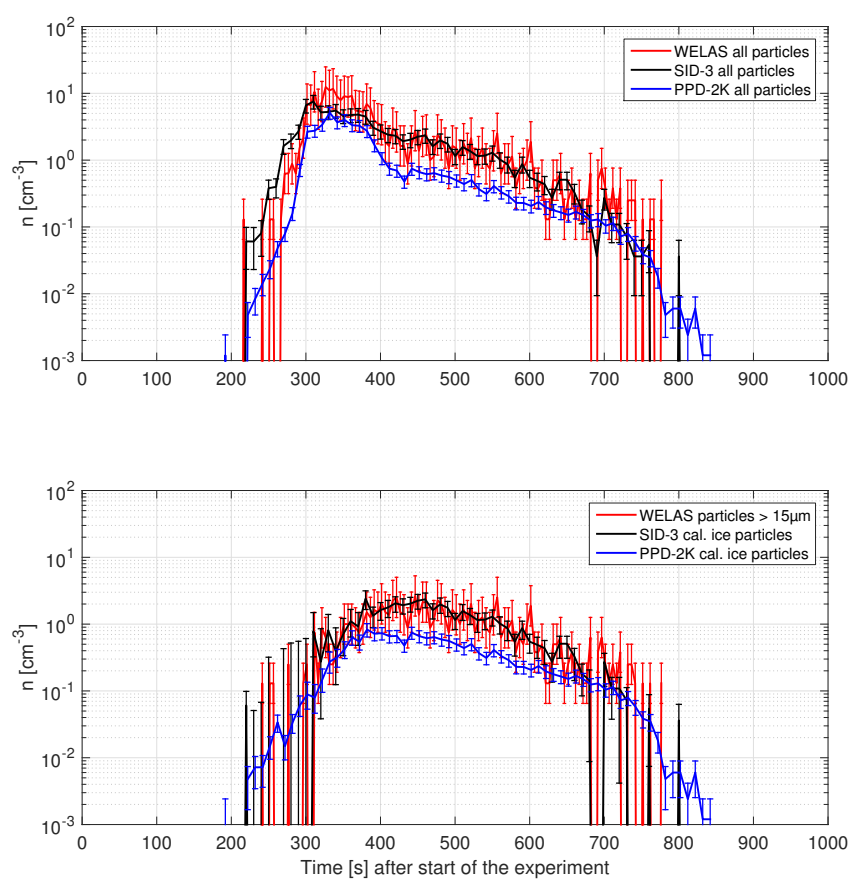

Figure 11. Comparison of number concentrations measured during AIDA RICE 03 expansion run 27. Upper panel: total number concentrations of the WELAS, the SID-3 and the PPD-2K. Lower panel: respective ice particle number concentrations.

sion, indicating that the MPC does not fully glaciate. The PPD-2K measurements show that droplets and ice particles coexisted for approximately $500 \mathrm{~s}$ and were in the same optical size range. In this case the PPD-2K data cannot simply be divided in ice and liquid by the introduction of a size threshold. Instead image analysis is necessary. Because of the used aerosol and the temperature range ( 243 to $253 \mathrm{~K}$ ) expansion run 46 is comparable to natural MPCs. This experiment also illustrates the nucleation of ice particles at temperatures of $253 \mathrm{~K}$. Unfortunately there are no SID-3 data available for this experiment. For $100 \mathrm{~s}<t<500 \mathrm{~s}$ the PPD-2K detected 532 ice particle scattering patterns. Of these patterns, $10.1 \pm 1.5 \%$ were classified as pristine and $89.9 \pm 5.7 \%$ as irregular. Thus the majority of the detected ice particle patterns in a MPC at the AIDA were irregular.

In conclusion this AIDA cloud chamber experiment demonstrates that the presented technique enables the discrimination between liquid water droplets and cloud ice particles at the same optical sizes in a range of $5 \mu \mathrm{m}<D_{\mathrm{p}}<$ $50 \mu \mathrm{m}$.

\subsection{Measurements during CLACE 2013}

The measurements presented in Fig. 13 were obtained on 24 February 2013. Panels a and b show the wind direction, wind speed, ambient temperature, and relative humidity recorded by MeteoSwiss at the Jungfraujoch station. The wind direc- 
(a)

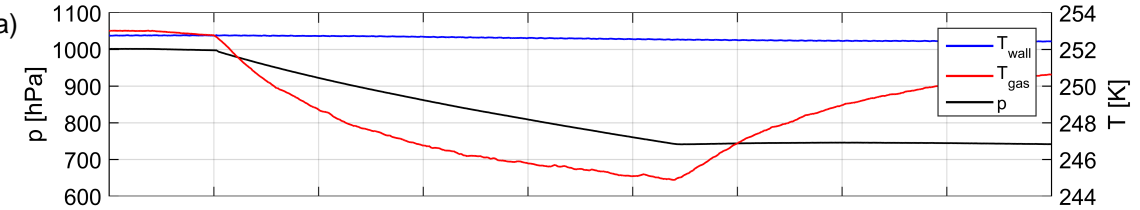

(b)

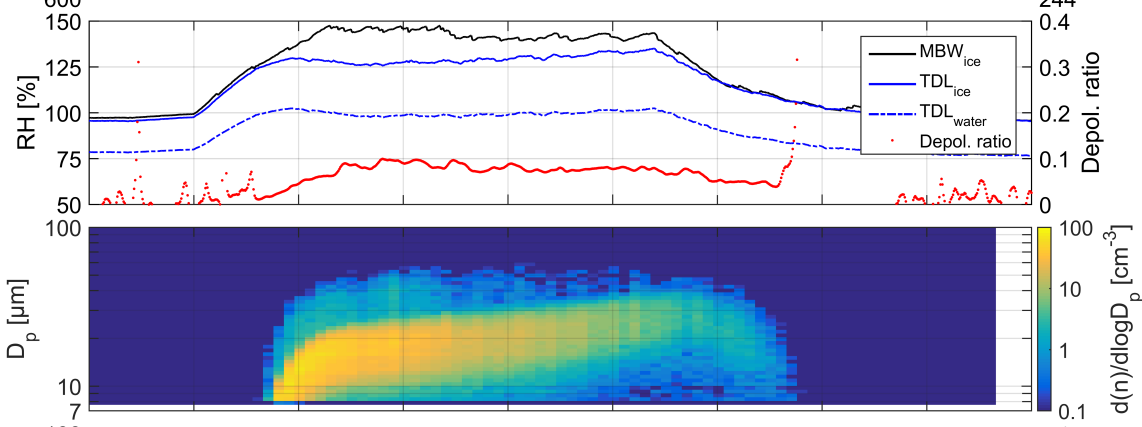

(d)

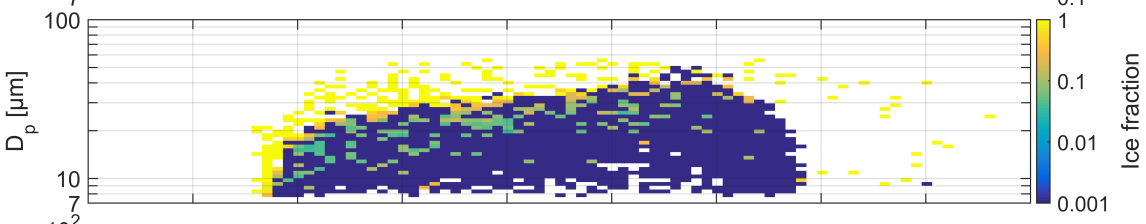

(e)

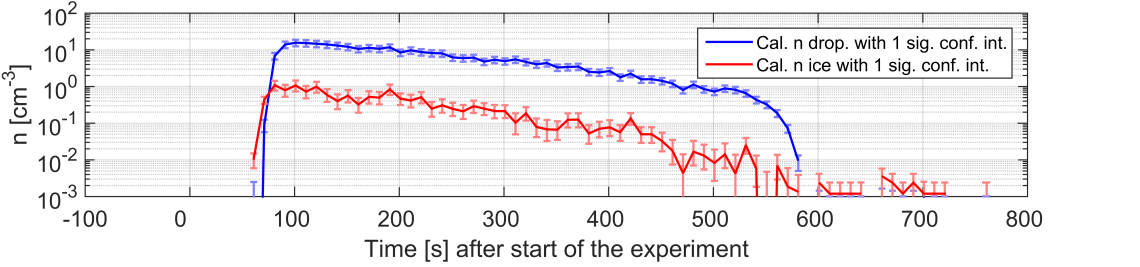

Figure 12. PPD-2K measurement, with $t_{\mathrm{av}}=10 \mathrm{~s}$, at the AIDA cloud chamber during RICE 03 campaign expansion run 46 . (a) displays the pressure and the temperature in the AIDA vessel during the experiment. (b) is a plot of the relative humidity in the chamber as well as the depolarization ratio measured by the SIMONE instrument. (c) shows the number size distribution as measured by the PPD-2K. (d) displays a size-resolved ice fraction over the course of the experiment. The ice fraction is calculated from the numbers of observed ice and droplet patterns. In (e) the calculated droplet and ice number concentrations are displayed.

tion and relative humidity measurements indicate that the site was permanently in clouds which approached the station from the south. The wind speed had a maximum between 22:00 and 23:00 UTC and the temperature was constantly decreasing. Panels c, d, and e show the SID-3 measurements and suggest that times of high total particle number concentrations (yellowish in panel c) are dominated by liquid droplets (blueish in panel d), while times of low total particle number concentrations (blueish in panel c) are dominated by ice particles (yellowish in panel d). Furthermore, one can deduce a temporal alternation between dense liquid and less dense glaciated cloud pockets.

A very interesting feature of these measurements is that the calculated small $\left(D_{\mathrm{p}}<20 \mu \mathrm{m}\right)$ ice particle number concentration correlates strongly with the wind speed whereas the calculated droplet number concentration does not (Fig. 13a and e and Fig. 14a and b). We propose two hypotheses for the correlation of wind speed and small ice particle number concentration.

The first hypothesis is linked to the fact that the wind direction at Jungfraujoch has a vertical component. If one thinks of the evolution history of the sampled cloud parcel, one notes that the higher the wind speed at the measurement site, the faster the cooling of the air parcel has happened (Hammer et al., 2014). A higher cooling rate leads to a higher ice production rate (Vali and Snider, 2015). The SID-3 probes the smallest ice particles which we expect to be freshly nucleated; thus the number concentration of small ice particles should be a measure for the ice nucleation rate. We expect small freshly nucleated ice particles to have irregular shapes.

The second hypothesis is that higher wind speeds could lead to more riming of cloud ice particles as well as more wind-blown particles lofted from the ground. The argument of wind-blown particles seems to contradict the observation that we did not detect wind-blown particles under cloud-free conditions. However when the station is in cloud, there can be a rapid rime buildup on all cloud-exposed surfaces of the station. During this buildup process wind might easily transport small ice particles from these surfaces to our instrument. We expect rime breakup particles to have columnar or platelike shapes. 
(a)

(b)
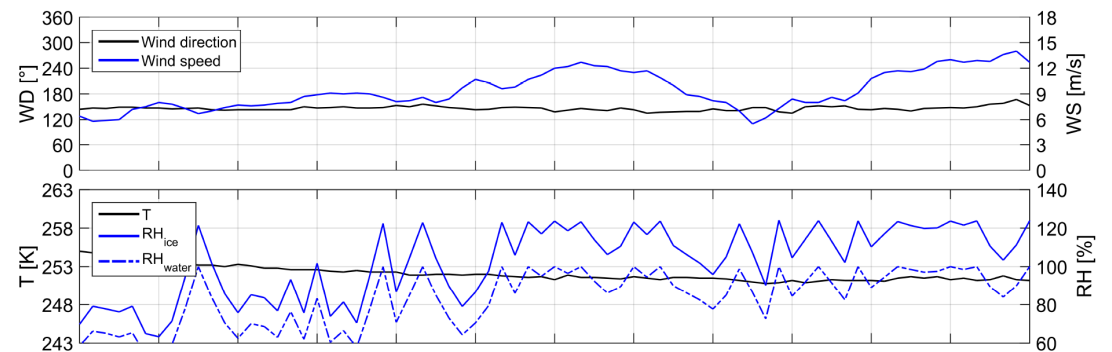

(c)

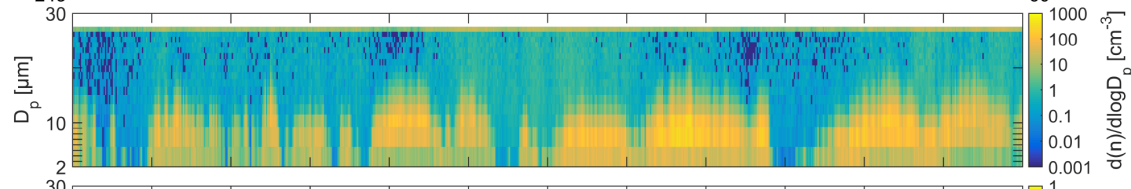

(d)

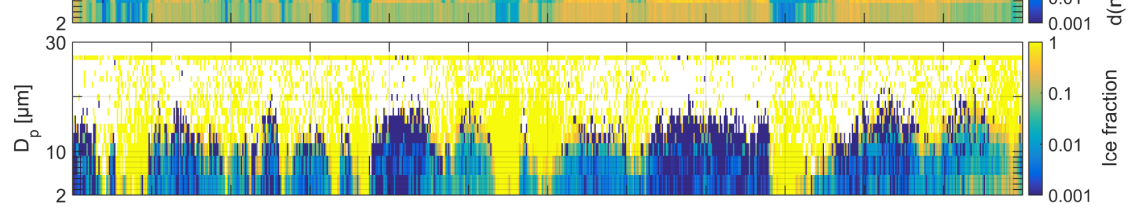

(e)

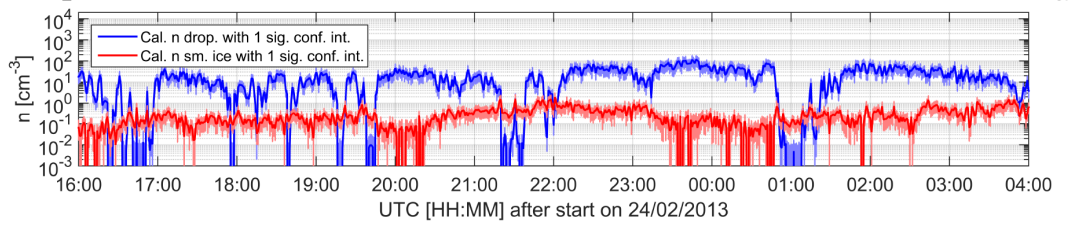

Figure 13. SID-3 measurements, with $t_{\mathrm{av}}=60 \mathrm{~s}$, taken during CLACE 2013 on the Jungfraujoch. (a) and (b): wind direction, wind speed, temperature, and relative humidity recorded by MeteoSwiss on the Jungfraujoch. (c) shows the number size distribution of cloud particles measured by the SID-3. (d) displays the size-resolved ice fraction over the measurement period. The ice fraction is calculated from the numbers of observed ice and droplet patterns. In (e) the calculated droplet and small ice $\left(D_{\mathrm{p}}<20 \mu \mathrm{m}\right)$ number concentrations are displayed.
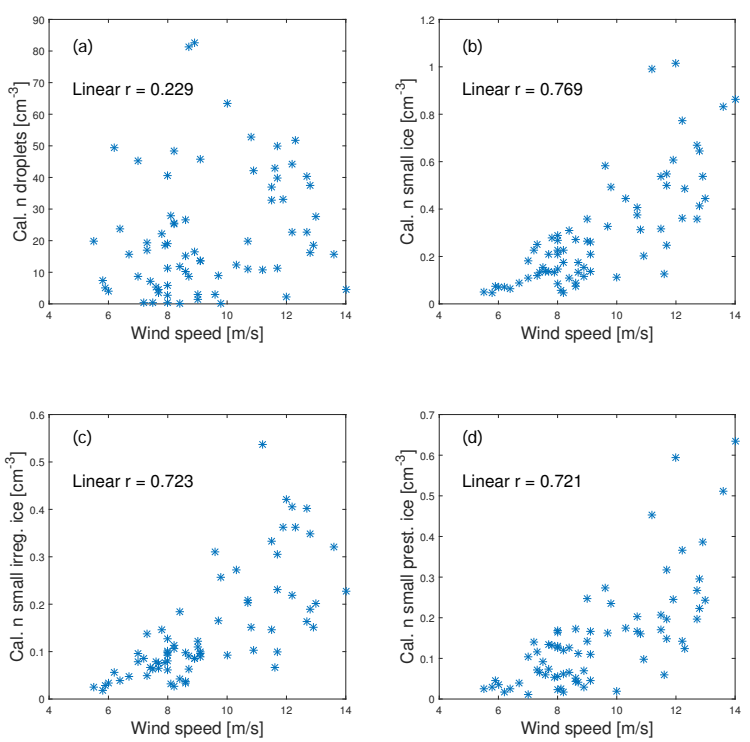

Figure 14. Correlation analysis of droplets as well as small ice particles $\left(D_{\mathrm{p}}<20 \mu \mathrm{m}\right)$ and the wind speed for the period displayed in Fig. 13. The figure shows as a function of the wind speed: the calculated droplet number concentration (a), the calculated small ice number concentration (b), the calculated small irregular ice number concentration (c), and the calculated small pristine ice (columnar and hexagonal) number concentration (d). In each plot the correlation coefficient, $r$, assuming a linear dependence is given.
Figure $14 \mathrm{c}$ and d display the result of a correlation analysis of small irregular and pristine ice particle number concentrations and the wind speed. Hereby pristine ice particles show columnar as well as hexagonal shapes. Both number concentrations of specific small ice particles correlate with the wind speed. Thus neither of the above-mentioned hypothesis can be ruled out based on the shape argument and there might have been several processes at work during the observational period. The presented finding of rather high ice particle number concentrations on Jungfraujoch is in accordance with a recently published study by Lloyd et al. (2015). In their work Lloyd et al. (2015) propose several ice formation pathways as an explanation. Further investigations for a wide range of wind speeds and with fast additional water vapor sensors are necessary to identify the processes behind these correlations.

In the left panel of Fig. 15 the $v_{\mathrm{az}}$ values are plotted against the particle size. Unfortunately, the clear separation seen in Fig. 10 is not reproduced in this plot. This is due to the presence of artifacts in the recorded droplet scattering patterns, as displayed in the right panel of Fig. 15. We succeeded in generating scattering patterns with the same artifacts when directing a particle ejected by the piezo electric injector at the edge of the sensitive volume of the instrument in the laboratory. In addition, coincident particle sampling can lead to scattering patterns with artifacts. As mentioned above in Sect. 2.2.1 the probability of coincident sampling by the SID- 

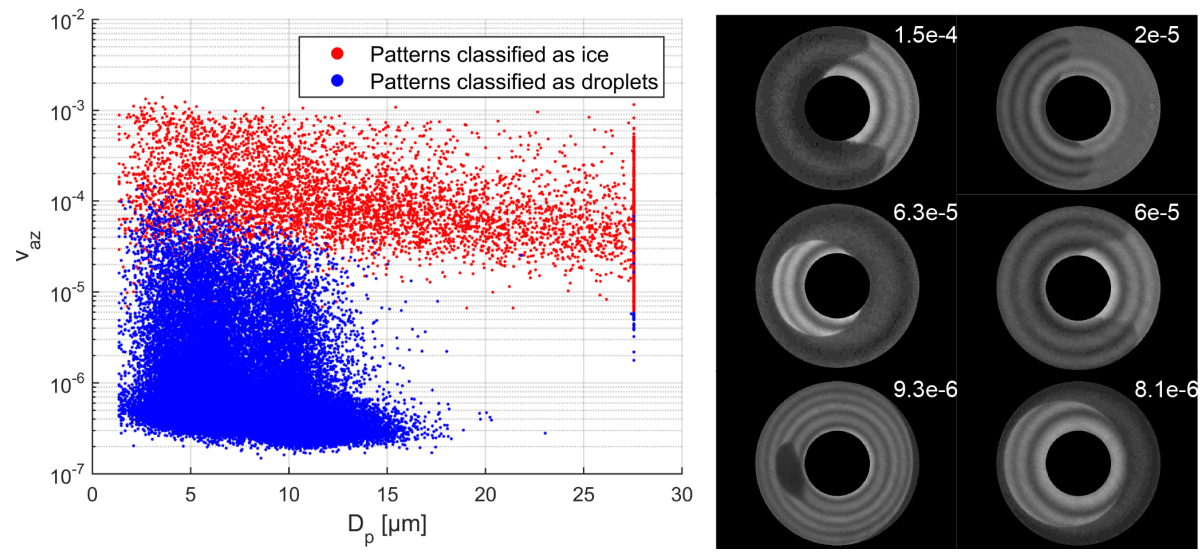

Figure 15. Image analysis for the period displayed in Fig. 13. Left panel: the variance of the polar integrated azimuthal profile as a function of the optical sphere equivalent diameter deduced from the trigger intensity for scattering patterns. For the automated classification a variance threshold was applied. Subsequently, patterns with $v_{\mathrm{az}}>2 \times 10^{-6}$ were manually crosschecked. Right panel: a selection of manually reclassified droplet patterns with artifacts. The $v_{\mathrm{az}}$ values are displayed with the patterns.

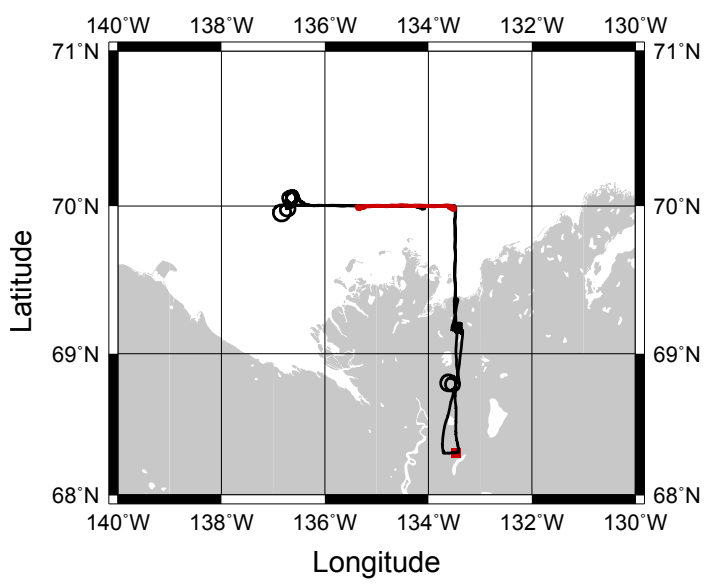

Figure 16. Track of VERDI Flight 7 from 29 April 2012. The red square marks the Mike Zubko Airport of Inuvik, NWT, Canada. The red line marks the flight track of the cloud profiling over the Beaufort Sea which is investigated further in this work.

3 camera is $1 \%$ for $n=103 \mathrm{~cm}^{-3}$. Such values are reached in times of high number concentrations (Fig. 13d). Thus we conclude that sampling at the edge of the sensitive volume and coincident particle sampling cause the scattering patterns with artifacts of Fig. 15.

The scattering patterns of droplets with artifacts have relatively high $v_{\mathrm{az}}$ values. For the presented data, 133284 droplet patterns and 6116 ice patterns were identified. For $v_{\mathrm{az}}^{\text {thr }}=$ $1 \times 10^{-5}, 2460$ droplet patterns with variance values above the threshold were manually reclassified. Thus the fraction of droplets with artifacts is rather low with $1.8 \%$ which is in accordance with the calculations from Sect. 2.3.1 for $n \approx 100 \mathrm{~cm}^{-3}$. However, as the ice fraction is $4.6 \%$ the contribution of the erroneously classified droplets by defining $v_{\mathrm{az}}^{\mathrm{thr}}$ is significant (one third), especially for small ice parti- cles. Unfortunately, the artifacts have a variable appearance which hinders an easy automated detection and thus makes a manual crosscheck currently necessary.

In summary, the investigated case study from Jungfraujoch demonstrates that the SID-3 is capable of discriminating liquid droplets and natural ice crystals in the same optical size range and detecting alternating liquid and glaciated cloud pockets during mountain top measurements, which is in agreement with the findings of Choularton et al. (2008).

\subsection{Measurements during VERDI}

Figure 16 depicts the flight path of the Polar-5 on 29 April 2012. The red part of the path depicts a straight flight leg over the Beaufort Sea during which the data displayed in Fig. 17 were obtained. During this period two vertical profiles through a typical Arctic mixed phase stratus were performed. The data are averaged for $15 \mathrm{~s}$ in order to get both a reasonable temporal resolution and sufficient statistics. Panel a of Fig. 17 displays the altitude of the aircraft and the ambient temperature measured by the Rosemount probe. Panel $\mathrm{b}$ displays both the number concentration of all particles and of the images recorded by the SID-3. The SID-3 measurements shown in panels $b, c$, and $d$ form the basis for the following cloud phase characterization: the aircraft descended through a dense purely liquid cloud (period A) into a less dense mixed phase region at the bottom of the cloud (period B). This was followed by an ascent through a dense liquiddominated mixed phase region (period C). The particle number size distribution, which is based on the trigger signal and displayed in panel c, indicates that the mean droplet diameter decreases from the top to the bottom of the cloud. At the bottom or lowermost parts of the cloud no clear droplet mode is noticeable. During the presented period the SID-3 detected 57 scattering patterns classified as ice particles, of which 
(a)

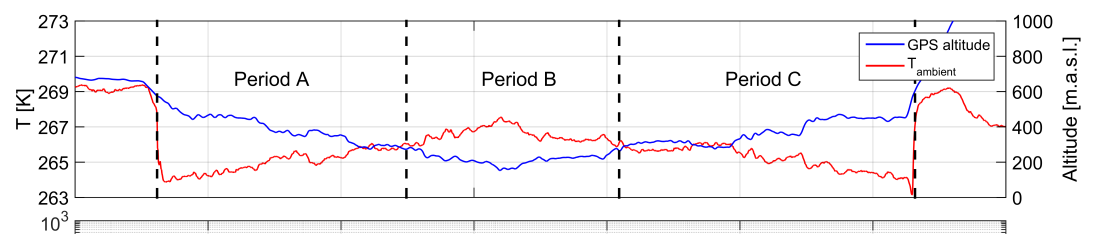

(b)

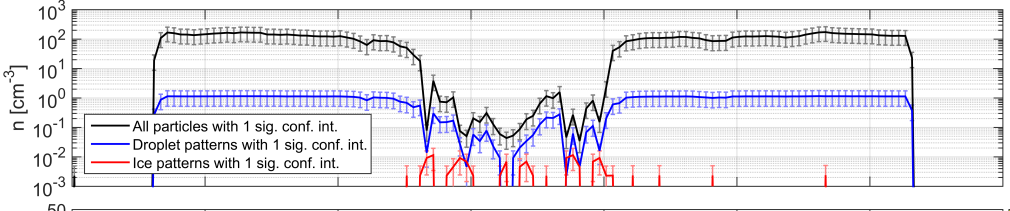

(c)

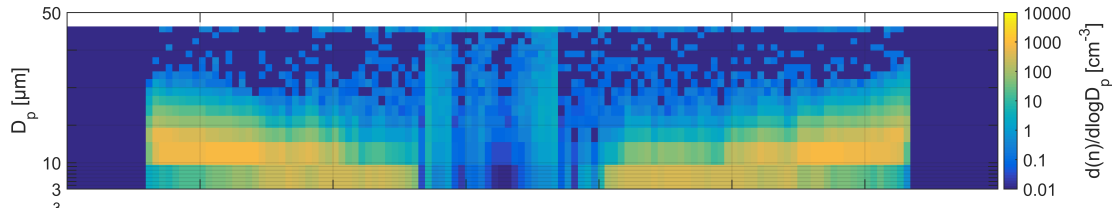

(d)

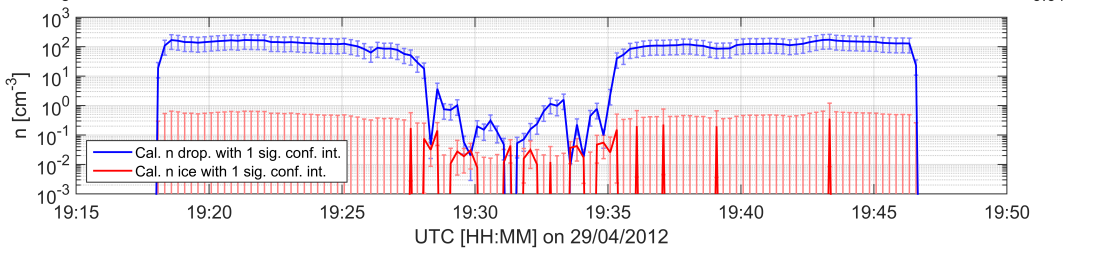

Figure 17. SID-3 measurements, with $t_{\mathrm{av}}=15 \mathrm{~s}$, from VERDI flight 7. In (a) the ambient temperature and altitude of the aircraft are displayed. Periods A and C mark a step-wise descent and ascent of the aircraft. During period B the altitude was relatively constant. (b) displays the particle and pattern number concentrations recorded by the SID-3. (c) shows the particle number size distribution. In (d) the calculated droplet and ice number concentrations are displayed.

$14.0 \pm 5.2 \%$ were pristine and $86 \pm 16.7 \%$ were irregular. These numbers illustrate that the vast majority of ice particle scattering patterns detected were irregular. During the periods $\mathrm{A}$ and $\mathrm{C}$ the number concentration was $n \approx 100 \mathrm{~cm}^{-3}$ and $0.21 \%$ of the scattering patterns recorded by the SID-3 contained artifacts. This shows that the given theoretical values for coincident particle sampling by the SID-3 camera of $1 \%$ for $n=103 \mathrm{~cm}^{-3}$ in Sect. 2.3.1 should be regarded as an upper boundary. Especially because most of the observed artifacts were similar to Fig. 15, indicating that they might originate from sampling at the edge of the sensitive volume.

In order to investigate the issue of subsampling, mentioned in Sect. 2.4, under real measurement conditions, the data from VERDI flight 7 are further analyzed in Fig. 18. Panel a displays the ice number concentration already shown in Fig. 17. For the results displayed in panel b and $\mathrm{c}$ of Fig. 18, it is assumed that the calculated mean ice concentration of period $\mathrm{B}$ is also present in periods $\mathrm{A}$ and $\mathrm{C}$. Panel $\mathrm{b}$ displays the values of the binomial probability distribution to detect no ice image, $B(x=0, p, N)$, with an assumed ice fraction of $p=\bar{n}_{\text {ice, period } \mathrm{B}} / n(t)$ for a temporal averaging time of $t_{\mathrm{av}}=15 \mathrm{~s} . \bar{n}_{\text {ice, period B }}$ is the calculated mean ice concentration during period $\mathrm{B}$ and $n(t)$ is the measured total number concentration per time step. The high probability to see no ice image during periods $\mathrm{A}$ and $\mathrm{C}$ is in agreement with the observation; it is not possible to state whether the constant ice concentration of period B was indeed present during periods $\mathrm{A}$ and $\mathrm{C}$ on the basis of an averaging time $t_{\mathrm{av}}=15 \mathrm{~s}$.
In Fig. 18c the data were averaged over the whole period A, lasting $550 \mathrm{~s}$, and period C, lasting $660 \mathrm{~s}$. Thus, the assumed ice fraction is calculated as $p=$ $\bar{n}_{\text {ice, period B }} / \bar{n}_{\text {Period A/C }}$, where $\bar{n}_{\text {Period A/C }}$ is the mean total number concentration for the entire periods $\mathrm{A}$ and $\mathrm{C}$. For period A, the probability distribution shows a maximum of four ice patterns, which is in contrast to the observation of no ice pattern. Thus one can conclude that the constant ice concentration of period B was not present during period A. For period $\mathrm{C}$, however, the observation of four ice patterns is in rather good agreement with the displayed probability distribution for period $\mathrm{C}$ and its maximum at five ice patterns. This suggests the conclusion that an ice number concentration comparable to that found during period B was also present during period $\mathrm{C}$.

This example illustrates that subsampling hinders statistically relevant statements for $t_{\mathrm{av}}=15 \mathrm{~s}$ (panel b of Fig. 18). For $t_{\mathrm{av}} \approx 500 \mathrm{~s}$ one can draw statistically relevant conclusions, but on a spatial resolution of approximately $30 \mathrm{~km}$. Such a resolution represents a limitation to resolve the spatial structure of MPCs with the SID-3. The critical variable in this context is the velocity at which the cloud passes the sampling volume of the instrument, which was given by the true airspeed of the aircraft of approximately $60 \mathrm{~m} \mathrm{~s}^{-1}$ during VERDI. 
(a)

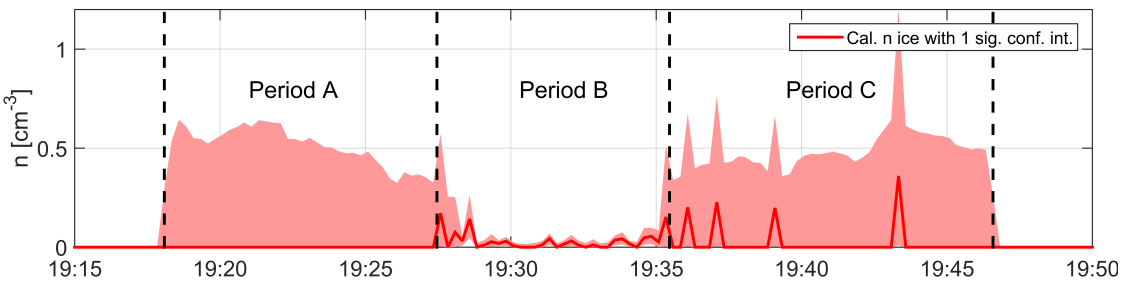

(b)

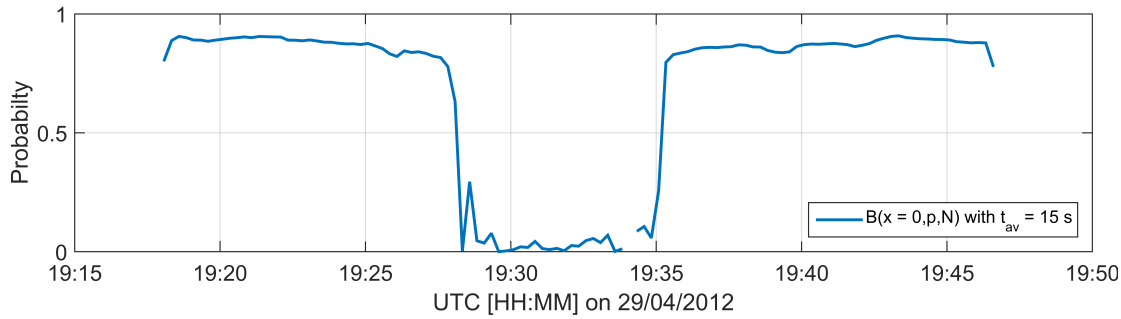

(c)

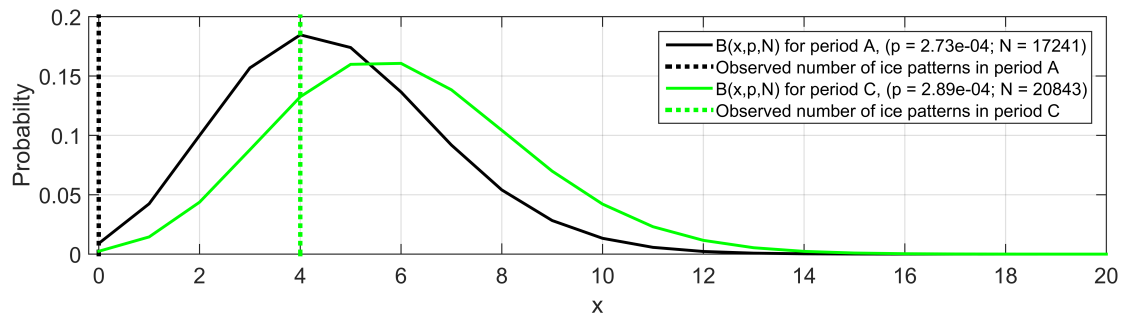

Figure 18. (a): deduced ice number concentrations during VERDI flight 7 already shown in Fig. 17d. (b): assuming the mean ice concentration of period $\mathrm{B}$ to be present in periods $\mathrm{A}$ and $\mathrm{C}$; the probability to find no ice $B(x=0, p, N)$ with $t_{\mathrm{av}}=15 \mathrm{~s}$ for the course of the measurement. (c): assuming the mean ice concentration of period $\mathrm{B}$ to be present in periods $\mathrm{A}$ and $\mathrm{C}$; binomial probability distributions for the occurrence of ice patterns for the entire periods A and C.

\section{Conclusions}

In this work we presented a technique to analyze SID-3 and PPD-2K in situ measurements of MPCs. A crucial step for MPC analysis is to distinguish between patterns that correspond to liquid water droplets and ice particles. In the case of droplet patterns we determine their size by fitting a Mie solution to the measured patterns. By doing so, the instruments are self calibrated with respect to particle size. From patterns corresponding to ice particles, the shape is deduced.

Within the analysis of AIDA laboratory measurements we demonstrated that the application of a size threshold to the PPD-2K data is not sufficient to distinguish between frozen (ice) and liquid (droplets) hydrometeors in a size range of $D_{\mathrm{p}} \in[5,50 \mu \mathrm{m}]$. A discrimination only became possible through the analysis of high-resolution scattering patterns, which is in accordance with results from alternative measurements. The deduced ice particle number concentrations of the SID-3 and PPD-2K compare well with those measured by the WELAS instrument permanently operated at the AIDA chamber. Furthermore, the cloud phase characterization of the SID-3 and PPD-2K, on the one hand, and of the SIMONE instrument, on the other hand, agree well.

Subsequently, we presented data obtained with the SID3 by sampling natural MPCs. For a case study from the
Jungfraujoch, the automated discrimination between ice and droplets needed a manual crosscheck due to artifacts in the scattering patterns. The results of this case study show an alternation in cloud characteristics from dense liquid to less dense glaciated, which is in agreement with earlier findings. Regarding the shape of the small ice particles they might originate from different ice formation processes (e.g., the two suggested mechanisms), taking place simultaneously.

The second case of natural clouds under investigation in this work are SID-3 measurements from the VERDI campaign performed in the Canadian Arctic. The analysis focused on the detection limit of the probe with regard to ice particles. The detection limit is reached in a situation of a high cloud particle sampling rate, due to the aircraft velocity and the total number concentration, and a low ice number concentration in the cloud. In order to draw statistically relevant conclusions the data need to be spatially averaged in the range of kilometers.

\section{The Supplement related to this article is available online at doi:10.5194/amt-9-159-2016-supplement.}


Acknowledgements. We acknowledge support by Deutsche Forschungsgemeinschaft (SCHN 1140/2-1 and SCHN 1140/1-2 within the HALO priority program 1294), the ACTRIS program (European Union Seventh Framework Program (FP7/2007-2013), grant 262254), the Open Access Publishing Fund of Karlsruhe Institute of Technology, the Helmholtz Association, and the Swiss National Science Foundation. We thank the AIDA team, the International Foundation High Altitude Research Stations Jungfraujoch and Gornergrat (HFSJG), and the VERDI team for their support and the opportunity to perform experiments. Furthermore we would like to thank P. Kaye, E. Hirst, and J. Ulanowski from the University of Hertfordshire for fruitful discussions and technical support in operating the SID-3 and PPD-2K. We thank two anonymous referees for their comments that helped to improve the manuscript.

The article processing charges for this open-access publication were covered by a Research

Centre of the Helmholtz Association.

Edited by: S. Malinowski

\section{References}

Abdelmonem, A., Schnaiter, M., Amsler, P., Hesse, E., Meyer, J., and Leisner, T.: First correlated measurements of the shape and light scattering properties of cloud particles using the new Particle Habit Imaging and Polar Scattering (PHIPS) probe, Atmos. Meas. Tech., 4, 2125-2142, doi:10.5194/amt-4-2125-2011, 2011.

Baltensperger, U., Schwikowski, M., Jost, D., Nyeki, S., Gäggeler, H., and Poulida, O.: Scavenging of atmospheric constituents in mixed phase clouds at the high-alpine site jungfraujoch part I: Basic concept and aerosol scavenging by clouds, Atmos. Environ., 32, 3975-3983, doi:10.1016/S1352-2310(98)00051-X, 1998.

Barlow, R.: Statistics: A Guide to the Use of Statistical Methods in the Physical Sciences, Wiley, 132-133, 1989.

Baumgardner, D., Brenguier, J., Bucholtz, A., Coe, H., DeMott, P., Garrett, T., Gayet, J., Hermann, M., Heymsfield, A., Korolev, A., Krämer, M., Petzold, A., Strapp, W., Pilewskie, P., Taylor, J., Twohy, C., Wendisch, M., Bachalo, W., and Chuang, P.: Airborne instruments to measure atmospheric aerosol particles, clouds and radiation: A cook's tour of mature and emerging technology, Atmos. Res., 102, 10-29, doi:10.1016/j.atmosres.2011.06.021, 2011.

Baumgardner, D., Newton, R., Krämer, M., Meyer, J., Beyer, A., Wendisch, M., and Vochezer, P.: The Cloud Particle Spectrometer with Polarization Detection (CPSPD): A next generation open-path cloud probe for distinguishing liquid cloud droplets from ice crystals, Atmos. Research, 142, 2-14, doi:10.1016/j.atmosres.2013.12.010, 2014.

Benz, S., Megahed, K., Möhler, O., Saathoff, H., Wagner, R., and Schurath, U.: T-dependent rate measurements of homogeneous ice nucleation in cloud droplets using a large atmospheric simulation chamber, J. Photochem. Photobiol. A, 176, 208-217, doi:10.1016/j.jphotochem.2005.08.026, 2005.
Bergeron, T.: Proces Verbaux de l'Association de Météorologie, chap. On the physics of clouds and precipitation, 156-178, Int. Union of Geodesy and Geophys., 1935.

Cantrell, W. and Heymsfield, A.: Production of Ice in Tropospheric Clouds: A Review, B. Am. Meteorol. Soc., 86, 795-807, doi:10.1175/BAMS-86-6-795, 2005.

Choularton, T. W., Bower, K. N., Weingartner, E., Crawford, I., Coe, H., Gallagher, M. W., Flynn, M., Crosier, J., Connolly, P., Targino, A., Alfarra, M. R., Baltensperger, U., Sjogren, S., Verheggen, B., Cozic, J., and Gysel, M.: The influence of small aerosol particles on the properties of water and ice clouds, Faraday Discuss., 137, 205-222, doi:10.1039/B702722M, 2008.

Cotton, R., Osborne, S., Ulanowski, Z., Hirst, E., Kaye, P. H., and Greenaway, R. S.: The Ability of the Small Ice Detector (SID-2) to Characterize Cloud Particle and Aerosol Morphologies Obtained during Flights of the FAAM BAe-146 Research Aircraft, J. Atmos. Oceanic Technol., 27, 290-303, doi:10.1175/2009JTECHA1282.1, 2010.

Cotton, R. J., Field, P. R., Ulanowski, Z., Kaye, P. H., Hirst, E., Greenaway, R. S., Crawford, I., Crosier, J., and Dorsey, J.: The effective density of small ice particles obtained from in situ aircraft observations of mid-latitude cirrus, Q. J. Roy. Meteor. Soc., 139, 1923-1934, doi:10.1002/qj.2058, 2013.

Findeisen, W.: Kolloid-meteorologische Vorgänge bei Niederschlagsbildung, Meteor. Z., 55, 121-133, 1938.

Fugal, J. P. and Shaw, R. A.: Cloud particle size distributions measured with an airborne digital in-line holographic instrument, Atmos. Meas. Tech., 2, 259-271, doi:10.5194/amt-2-259-2009, 2009.

Hammer, E., Bukowiecki, N., Gysel, M., Jurányi, Z., Hoyle, C. R., Vogt, R., Baltensperger, U., and Weingartner, E.: Investigation of the effective peak supersaturation for liquid-phase clouds at the high-alpine site Jungfraujoch, Switzerland (3580 m a.s.1.), Atmos. Chem. Phys., 14, 1123-1139, doi:10.5194/acp-14-11232014, 2014.

Hare, D. E. and Sorensen, C. M.: The density of supercooled water. II. Bulk samples cooled to the homogeneous nucleation limit, J. Chem. Phys., 87, 4840-4845, doi:10.1063/1.453710, 1987.

Henneberger, J., Fugal, J. P., Stetzer, O., and Lohmann, U.: HOLIMO II: a digital holographic instrument for ground-based in situ observations of microphysical properties of mixed-phase clouds, Atmos. Meas. Tech., 6, 2975-2987, doi:10.5194/amt-62975-2013, 2013.

Hirst, E., Kaye, P., Greenaway, R., Field, P., and Johnson, D.: Discrimination of micrometre-sized ice and super-cooled droplets in mixed-phase cloud, Atmos. Environ., 35, 33-47, doi:10.1016/S1352-2310(00)00377-0, 2001.

Intrieri, J. M., Shupe, M. D., Uttal, T., and McCarty, B. J.: An annual cycle of Arctic cloud characteristics observed by radar and lidar at SHEBA, J. Geophys. Res., 107, SHE 5-1-SHE 5-15, doi:10.1029/2000JC000423, 2002.

Järvinen, E., Vochezer, P., Möhler, O., and Schnaiter, M.: Laboratory study of microphysical and scattering properties of corona-producing cirrus clouds, Appl. Opt., 53, 7566-7575, doi:10.1364/AO.53.007566, 2014.

Johnson, A., Lasher-Trapp, S., Bansemer, A., Ulanowski, Z., and Heymsfield, A. J.: Difficulties in Early Ice Detection with the Small Ice Detector-2 HIAPER (SID-2H) in Maritime Cumuli, J. 
Atmos. Oceanic Technol., 31, 1263-1275, doi:10.1175/JTECHD-13-00079.1, 2014.

Kaye, P. H., Hirst, E., Greenaway, R. S., Ulanowski, Z., Hesse, E., DeMott, P. J., Saunders, C., and Connolly, P.: Classifying atmospheric ice crystals by spatial light scattering, Opt. Lett., 33, 1545-1547, doi:10.1364/OL.33.001545, 2008.

Klingebiel, M., de Lozar, A., Molleker, S., Weigel, R., Roth, A., Schmidt, L., Meyer, J., Ehrlich, A., Neuber, R., Wendisch, M., and Borrmann, S.: Arctic low-level boundary layer clouds: in situ measurements and simulations of mono- and bimodal supercooled droplet size distributions at the top layer of liquid phase clouds, Atmos. Chem. Phys., 15, 617-631, doi:10.5194/acp-15617-2015, 2015.

Kupiszewski, P., Weingartner, E., Vochezer, P., Schnaiter, M., Bigi, A., Gysel, M., Rosati, B., Toprak, E., Mertes, S., and Baltensperger, U.: The Ice Selective Inlet: a novel technique for exclusive extraction of pristine ice crystals in mixed-phase clouds, Atmos. Meas. Tech., 8, 3087-3106, doi:10.5194/amt-8-30872015, 2015.

Lance, S., Brock, C. A., Rogers, D., and Gordon, J. A.: Water droplet calibration of the Cloud Droplet Probe (CDP) and inflight performance in liquid, ice and mixed-phase clouds during ARCPAC, Atmos. Meas. Tech., 3, 1683-1706, doi:10.5194/amt3-1683-2010, 2010.

Lloyd, G., Choularton, T. W., Bower, K. N., Gallagher, M. W., Connolly, P. J., Flynn, M., Farrington, R., Crosier, J., Schlenczek, O., Fugal, J., and Henneberger, J.: The origins of ice crystals measured in mixed-phase clouds at the high-alpine site Jungfraujoch, Atmos. Chem. Phys., 15, 12953-12969, doi:10.5194/acp15-12953-2015, 2015.

McFarlane, S. A. and Marchand, R. T.: Analysis of ice crystal habits derived from MISR and MODIS observations over the ARM Southern Great Plains site, J. Geophys. Res.-Atmos., 113, D07209, doi:10.1029/2007JD009191, 2008.

McFarquhar, G. M., Um, J., and Jackson, R.: Small Cloud Particle Shapes in Mixed-Phase Clouds, J. Appl. Meteor. Climatol., 52, 1277-1293, doi:10.1175/JAMC-D-12-0114.1, 2013.

Mie, G.: Beiträge zur Optik trüber Medien, speziell kolloidaler Metallösungen, Annalen der Physik, 330, 377-445, doi:10.1002/andp.19083300302, 1908.

Mioche, G., Jourdan, O., Ceccaldi, M., and Delanoë, J.: Variability of mixed-phase clouds in the Arctic with a focus on the Svalbard region: a study based on spaceborne active remote sensing, Atmos. Chem. Phys., 15, 2445-2461, doi:10.5194/acp-15-24452015, 2015.

Möhler, O., Büttner, S., Linke, C., Schnaiter, M., Saathoff, H., Stetzer, O., Wagner, R., Krämer, M., Mangold, A., Ebert, V., and Schurath, U.: Effect of sulfuric acid coating on heterogeneous ice nucleation by soot aerosol particles, J. Geophys. Res.-Atmos., 110, D11210, doi:10.1029/2004JD005169, 2005.

Morrison, H., de Boer, G., Feingold, G., Harrington, J., Shupe, M. D., and Sulia, K.: Resilience of persistent Arctic mixed-phase clouds, Nature Geosci., 5, 11-17, doi:10.1038/ngeo1332, 2012.

Pruppacher, H. R. and Klett, J. D.: Microphysics of clouds and precipitation, Kluwer Academic Publishers, Dordrecht, the Netherlands, 118-144, 1997.

Schmidt, S., Schneider, J., Klimach, T., Mertes, S., Schenk, L. P., Curtius, J., Kupiszewski, P., Hammer, E., Vochezer, P., Lloyd, G., Ebert, M., Kandler, K., Weinbruch, S., and Borrmann, S.: In-situ single submicron particle composition analysis of ice residuals from mountain-top mixed-phase clouds in Central Europe, Atmos. Chem. Phys. Discuss., 15, 4677-4724, doi:10.5194/acpd15-4677-2015, 2015.

Schnaiter, M., Büttner, S., Möhler, O., Skrotzki, J., Vragel, M., and Wagner, R.: Influence of particle size and shape on the backscattering linear depolarisation ratio of small ice crystals - cloud chamber measurements in the context of contrail and cirrus microphysics, Atmos. Chem. Phys., 12, 10465-10484, doi:10.5194/acp-12-10465-2012, 2012.

Schnaiter, M., Järvinen, E., Vochezer, P., Abdelmonem, A., Wagner, R., Jourdan, O., Mioche, G., Shcherbakov, V. N., Schmitt, C. G., Tricoli, U., Ulanowski, Z., and Heymsfield, A. J.: Cloud chamber experiments on the origin of ice crystal complexity in cirrus clouds, Atmos. Chem. Phys. Discuss., 15, 30511-30561, doi:10.5194/acpd-15-30511-2015, 2015.

Segelstein, D. J.: The Complex Refractive Index of Water, Master's thesis, University of Missouri-Kansas City, 116-144, 1981.

Shupe, M. D., Matrosov, S. Y., and Uttal, T.: Arctic MixedPhase Cloud Properties Derived from Surface-Based Sensors at SHEBA, J. Atmos. Sci., 63, 697-711, doi:10.1175/JAS3659.1, 2006.

Skrotzki, J., Connolly, P., Schnaiter, M., Saathoff, H., Möhler, O., Wagner, R., Niemand, M., Ebert, V., and Leisner, T.: The accommodation coefficient of water molecules on ice - cirrus cloud studies at the AIDA simulation chamber, Atmos. Chem. Phys., 13, 4451-4466, doi:10.5194/acp-13-4451-2013, 2013.

Spiegel, J. K., Zieger, P., Bukowiecki, N., Hammer, E., Weingartner, E., and Eugster, W.: Evaluating the capabilities and uncertainties of droplet measurements for the fog droplet spectrometer (FM-100), Atmos. Meas. Tech., 5, 2237-2260, doi:10.5194/amt5-2237-2012, 2012.

Stopford, C., Ulanowski, Z., Hesse, E., Kaye, P., Hirst, E., and Schnaiter, M.: Initial investigation into using Fourier spectra as a means of classifying ice crystal shapes, in: Proceedings of the 11th International Conference on Electromagnetic and Light Scattering, 7-12 September 2008, Hatfield, 247-250, 2008.

Sun, Z. and Shine, K. P.: Studies of the radiative properties of ice and mixed-phase clouds, Q.J Royal Met. Soc., 120, 111-137, doi:10.1002/qj.49712051508, 1994.

Tricoli, U., Vochezer, P., and Pfeilsticker, K.: Transition operator calculation with the Green's dyadic technique for electromagnetic scattering: a numerical approach using the Dyson equation, J. Quant. Spectrosc. Radiat. Transfer, 162, 77-88, doi:10.1016/j.jqsrt.2015.04.006, 2015.

Ulanowski, Z., Hesse, E., Kaye, P. H., and Baran, A. J.: Light scattering by complex ice-analogue crystals, J. Quant. Spectrosc. Ra., 100, 382-392, doi:10.1016/j.jqsrt.2005.11.052, 2006.

Ulanowski, Z., Stopford, C., Hesse, E., Kaye, P. H., Hirst, E., and Schnaiter, M.: Characterization of small ice crystals using frequency analysis of azimuthal scattering patterns, in: PeerReviewed Abstracts of the Tenth Conference on Electromagnetic and Light Scattering, 17-23 June 2007, Bodrum, 225-228, 2007.

Ulanowski, Z., Hirst, E., Kaye, P., and Greenaway, R.: Retrieving the size of particles with rough and complex surfaces from twodimensional scattering patterns, J. Quant. Spectrosc. Ra., 113, 2457-2464, doi:10.1016/j.jqsrt.2012.06.019, 2012.

Ulanowski, Z., Kaye, P. H., Hirst, E., Greenaway, R. S., Cotton, R. J., Hesse, E., and Collier, C. T.: Incidence of rough and irregu- 
lar atmospheric ice particles from Small Ice Detector 3 measurements, Atmos. Chem. Phys., 14, 1649-1662, doi:10.5194/acp14-1649-2014, 2014.

Vali, G. and Snider, J. R.: Time-dependent freezing rate parcel model, Atmos. Chem. Phys., 15, 2071-2079, doi:10.5194/acp15-2071-2015, 2015.

Wagner, R., Möhler, O., Saathoff, H., Schnaiter, M., and Leisner, T.: New cloud chamber experiments on the heterogeneous ice nucleation ability of oxalic acid in the immersion mode, Atmos. Chem. Phys., 11, 2083-2110, doi:10.5194/acp-11-2083-2011, 2011.

Wegener, A.: Thermodynamik der Atmosphäre, edited by: Barth, J. A., Leipzig, 1911.
Wendisch, M. and Brenguier, J.-L.: Airborne Measurements for Environmental Research, Wiley-Blackwell, 225-301, doi:10.1002/9783527653218, 2013.

Worringen, A., Kandler, K., Benker, N., Dirsch, T., Mertes, S., Schenk, L., Kästner, U., Frank, F., Nillius, B., Bundke, U., Rose, D., Curtius, J., Kupiszewski, P., Weingartner, E., Vochezer, P., Schneider, J., Schmidt, S., Weinbruch, S., and Ebert, M.: Singleparticle characterization of ice-nucleating particles and ice particle residuals sampled by three different techniques, Atmos. Chem. Phys., 15, 4161-4178, doi:10.5194/acp-15-4161-2015, 2015. 